Original Research Paper

\title{
Energy Audit of Health Care Facilities: Dynamic Simulation of Energy Performances and Energy-Oriented Refurbishment of System and Equipment for Microclimatic Control
}

\author{
${ }^{1}$ Fabrizio Ascione, ${ }^{2}$ Nicola Bianco, ${ }^{3}$ Rosa Francesca De Masi, \\ ${ }^{4}$ Filippo de Rossi, ${ }^{5}$ Claudio De Stasio and ${ }^{6}$ Giuseppe Peter Vanoli \\ ${ }^{1,2,5}$ Department of Industrial Engineering, Università degli Studi di Napoli Federico II, 80125 Napoli, Italy \\ ${ }^{3,4,6}$ Department of Engineering, Università degli Studi del Sannio, 82100 Benevento, Italy
}

Article history

Received: 25-11-2015

Revised: 27-11-2015

Accepted: 09-01-2016

Corresponding Author:

Fabrizio Ascione

Department of Industrial

Engineering, Università degli

Studi di Napoli Federico II,

80125 Napoli, Italy

Email: fabrizio.ascione@unina.it

\begin{abstract}
Topic of the study is the investigation of potentialities of energy simulation for optimizing the building refurbishment, by taking into account impacts of both envelope renovation and HVAC system selection. Energy audit and refurbishment of the Day-Hospital building of a great Italian health care facility are proposed. A meticulous energy diagnosis of the base case building and design of a complete renovation- by improving both building envelope and HVAC systems- are presented. All data and boundary conditions for dynamic energy investigations have been carefully selected, also by means of in-situ studies, in order to provide a reliable model. In particular, several energy efficiency measures, with reference to building envelope and HVAC systems, are analyzed and it will be evidenced that, step-by-step, a proper design, supported by the adoption of numerical studies, may optimize the energy performances of the building, as well as the indoor microclimatic control.
\end{abstract}

Keywords: Energy Retrofit, Hospital Buildings, Numerical and Experimental Studies, Energy Simulation, Building Envelope, HVAC Systems

\section{Introduction}

\section{Hospitals and Air-Conditioning}

The paper provides suggestions for energy audit of large health facilities, by underlining that the building energy simulation may be useful in order to design proper refurbishments and new energy-efficient buildings (Harries et al., 2013). The steady-state approach is usually adopted for evaluating heating and cooling loads at rated conditions and thus it is proper for sizing the HVAC system. No useful information, conversely, can be provided for improving annual energy performances and in order to select the most suitable renovation measures. Analogously, energy audits based on steady-state energy evaluations, by adopting conventional boundary conditions, could be proper for energy certifications, without providing suitable suggestions for the energy improvement of specific buildings.

More in detail, health care facilities are critical applications for both microclimatic control and energy savings. High complexity and a required rigorous microclimatic control make the design and, above all, the refurbishment of hospitals quite difficult. Within this frame, energy saving goals, although not overriding, however demand careful consideration, because well-insulated buildings and well selected/sized air-conditioning systems usually allow also higher microclimatic stability, by improving, therefore, the indoor comfort conditions.

The most important guidelines during the designing phase are the high levels of microclimatic control, indoor air, air tightness and filtrations, in order to protect the patients from the external conditions and, sometimes, at conversely. Obviously, the very different hosted functions have quite different requirements, in terms of indoor set points and amount of outdoor ventilation.

The highest control is required for white rooms, surgery blocks, wards for immune-deficient patients or infectious ones, as well as with reference to intensive care units. Conversely, several other spaces - as, for instance, administrative offices, ambulatories, generic wards- require standard control strategies. Several technical associations have proposed design guidelines for hospitals, such as the American Institute of 
Architects (AIA, 2006) and the American Society for Heating, Refrigerating and Air-Conditioning Engineers (ASHRAE, 2011; 1999). Other useful documents can be found at European (DIN, 2003) and/or National levels. In Italy, the most important prescriptions have been provided by the Ministerial Act 13011/1974 (IMPW, 1974), a dedicated Presidential Decree (PIR, 1997) and by the guidelines of ISPESL (ISPESL, 2002).

Table 1, re-written starting by (Stefanutti, 1996), summarizes relevant design conditions for typical hospital departments. Often, the ventilation is responsible of the highest energy losses, mainly because of the relative humidity control (Harriman et al., 2001). When 5,10 or $15 \mathrm{ACH}$ are required (e.g., in the surgery blocks), the role of the building envelope could seem marginal, while the efficiency of air-conditioning systems becomes primary, above all when recirculation and heat recovery are not admitted in order to avoid risk of contaminations. Really, this is not always true, as underlined in (Ascione et al., 2013a).

In general, for this kind of application, thermalhygrometric control of health care facilities, guaranteed by a strong use of air-conditioning system, is very energy intensive (Lomas and Giridharan, 2012; Lomas et al., 2013; Short et al., 2012). In particular, the close correlation between ventilation air and latent loads makes hospitals critical applications. The need of a suitable thermal environment, with reference to buildings that host sick patients, has been already underlined by Van Hoof et al. (2010a; 2010b), being the diseases due to the poor air quality a frequent problem of health care facilities (Ozyogurtcu et al., 2010; San José-Alonso et al., 1999; Balaras et al., 2007).

Really, the need to combine energy conservation and proper ventilation was investigated in ( $\mathrm{Yu}$ and $\mathrm{Kim}$, 2012) for housing buildings. With reference to the role played by the air-conditioning systems, recently (Sun et al., 2011) proposed a quite new control strategy for multi-zone VAV HVAC systems (i.e., variable air volume), suitable to guarantee both adequate indoor air quality and energy savings. In the same direction, the paper (Cao et al., 2013) evidences that an excessive use of air-conditioning has negative effects:

The study here proposed examines these relevant points, with reference to a case study: the Day-Hospital building of the health care institute "G. Pascale". Dynamic energy simulations- by means of EnergyPlus 7.2.0 (DOE, 2012)- have been used in order to optimize the energy refurbishment of the building, starting by input data directly surveyed in-situ and then by carrying out deep feasibility studies concerning the envelope renovation, the necessary values of indoor parameters according to the zones' uses, the HVAC solutions. All told, by showing all relevant design stages, the paper tries to suggest a gradual methodological approach for the refurbishment of health care facilities, one of the most complex applications of thermo-hygrometric active control.

\section{Presentation of the Case-Study}

Naples (Italy) localized all main hospitals on the hill area. Among these, there is the National Institute for the Cancer Treatment "G. Pascale", shown in Fig. 1. Recently, the Institute won a European Competition, partly funded by the EU, in order to improve energy performances of building envelopes and active systems, by guarantying, at the same time, improvement of indoor comfort. The renovation phase initially involved only the Day-Hospital block. The building has six floors, in addition to the basement story. The area of each floor is $1530 \mathrm{~m}^{2}$, while the building overall height is around $27 \mathrm{~m}$, the indoor floor surface is $10^{\prime} 190 \mathrm{~m}^{2}$, the gross volume is $41^{\prime} 834$ $\mathrm{m}^{3}$. About the building characteristics, the previous energy quality was quite poor. In particular, the following envelope components, characterizing the building before the renovation, have been here considered for the base scenario:

- The external walls had composite structures, with an overall $\mathrm{U}_{\text {value }}$ around $1.30 \mathrm{~W} / \mathrm{m}^{2} \mathrm{~K}$ (this average value takes into account also the thermal bridges). The $U_{\text {value }}$ has been calculated by considering three different sub-structures: (a) The structural frame of pillars and beams in reinforced concrete; (b) the wall with hollow blocks, air-gap $(15 \mathrm{~cm})$ and an external layer with semi-hollow bricks; (c) the sections above and below the windows, characterized by lower thicknesses, with a single layer of hollow blocks and inner and outer plasters

- Ceiling, basement and roofs had mixed structures, given by the parallel presence of concrete beams, joists and interposed hollow bricks, without insulating layers. The $U_{\text {value }}$ was around $2.86 \mathrm{~W} / \mathrm{m}^{2} \mathrm{~K}$

- The window frames had a metallic composition, without thermal breaks. The windows were double-glazed, with thicknesses equal to $3 / 6 / 3$ (i.e., inner glass/cavity/outer glass). The window gap was air-filled, with an overall $\mathrm{U}_{\mathrm{W}}$ equal to around $3.2 \mathrm{~W} / \mathrm{m}^{2} \mathrm{~K}$

The methodology for detecting the $U_{\text {values }}$ of the building structures is described in the following subsection 3.1. 
Table 1. Design conditions for hospital wards

\begin{tabular}{llll}
\hline Sector & Air Changes $\left(\mathrm{h}^{-1}\right)$ & Winter $($ Summer $) \mathrm{T}\left({ }^{\circ} \mathrm{C}\right)$ & $\mathrm{RH}(\%)$ \\
\hline Contagious & $2-5$ & $21 / 23(24 / 26)$ & $40 / 55$ \\
Immun. deficient & $2-5$ & $22 / 24(24 / 26)$ & $40 / 55$ \\
Intensive care & 2 & $22 / 24(26)$ & $40 / 55$ \\
Hospital Ward & 2 & $21 / 23(26)$ & $40 / 55$ \\
Pharmacy & 2 & $19 / 21(24 / 27)$ & $40 / 60$ \\
Physiotherapy & 2 & $19 / 21(24 / 27)$ & $40 / 60$ \\
Surgery & 15 & $22(26)$ & $45 / 60$ \\
Traumatized & 5 & $22(26)$ & $40 / 60$ \\
Toilettes & --- & $19 / 21(24 / 27)$ & $40 / 60$ \\
Kitchens & 2 & $19 / 21(25 / 27)$ & $40 / 60$ \\
\hline
\end{tabular}
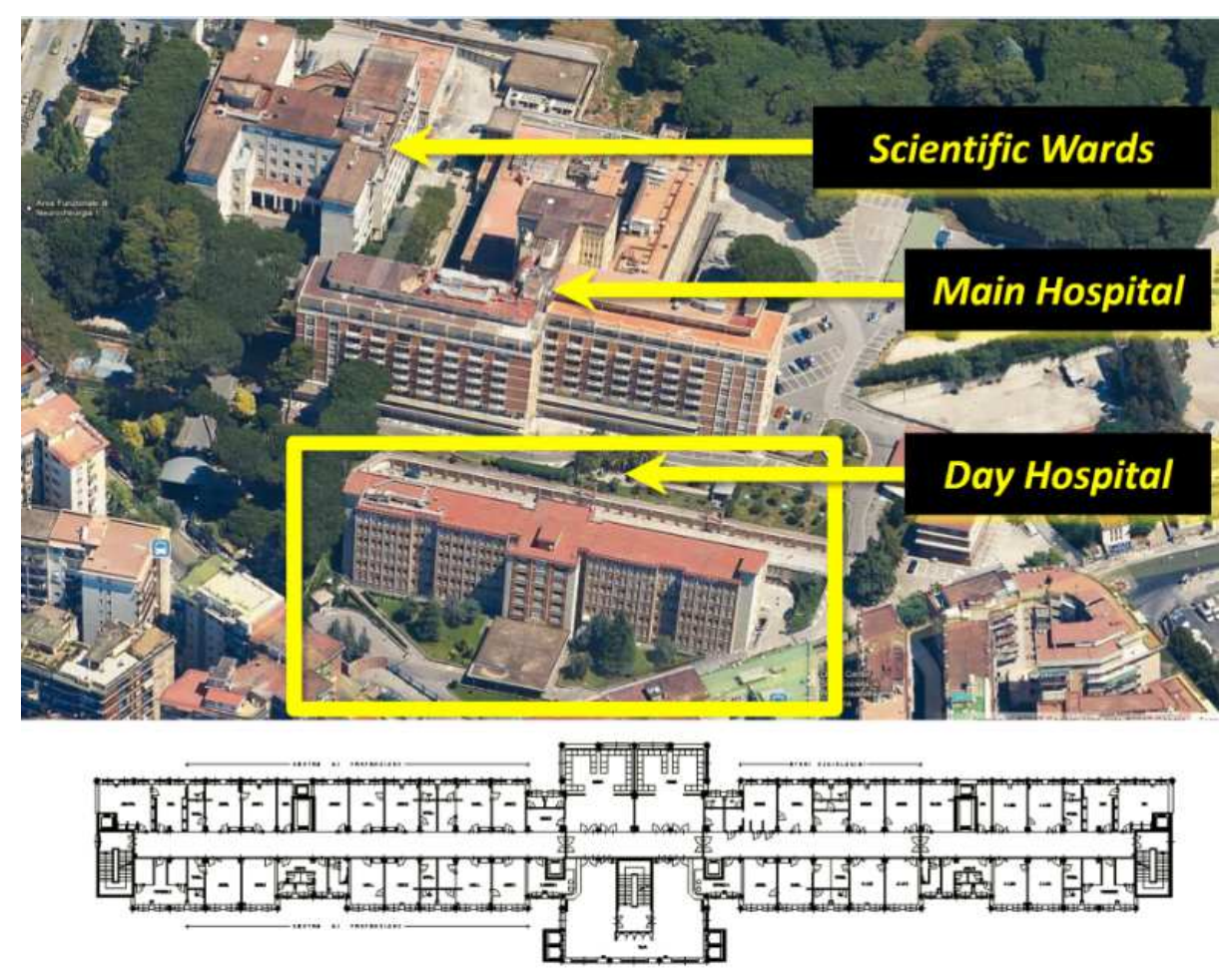

Fig. 1. Area of "G. Pascale" Hospital and various buildings

With reference to the heating and cooling systems, the entire hospital park was equipped with centralized generators of hot water, used for the space heating and necessities of DHW. In particular, 4 steam boilers (fired with natural gas from the city grid) provided hot fluid to several heat exchangers. The total thermal capacity was $8000 \mathrm{~kW}$. Boilers and main circulation pumps were placed at the buried floor of the main hospital building (Fig. 1), while the heat exchangers were decentralized at each block. For the space heating, heat exchangers provided thermal fluid at 55 ${ }^{\circ} \mathrm{C}$, usable for the in-room terminals (i.e., convectors, fan coil, baseboard heaters) and for the heating coils of the air-handling units. The office building was equipped with an autonomous gas boiler.

Conversely, the cooling systems were diversified for each building. The main building was equipped with two air-cooled chillers, each one with a cooling capacity of $700 \mathrm{~kW}$. Other devices were installed close to each building. During the last years, several malfunctions affected the operations. Therefore, beyond the main devices, packaged air-conditioners were installed in various periods, in order to allow indoor comfort conditions by means of "ready-to-use" systems, based on the direct expansion technology.

As previously cited, this study will discuss energy conservation measures for the Day-Hospital block, being this the one interested, today, by a deep renovation. Several studies have been carried out in order to identify the most effective actions for improving the indoor conditions and make the building "a best practice" in energy efficiency. Figure 2 summarizes the logical structure of the performed investigations. 


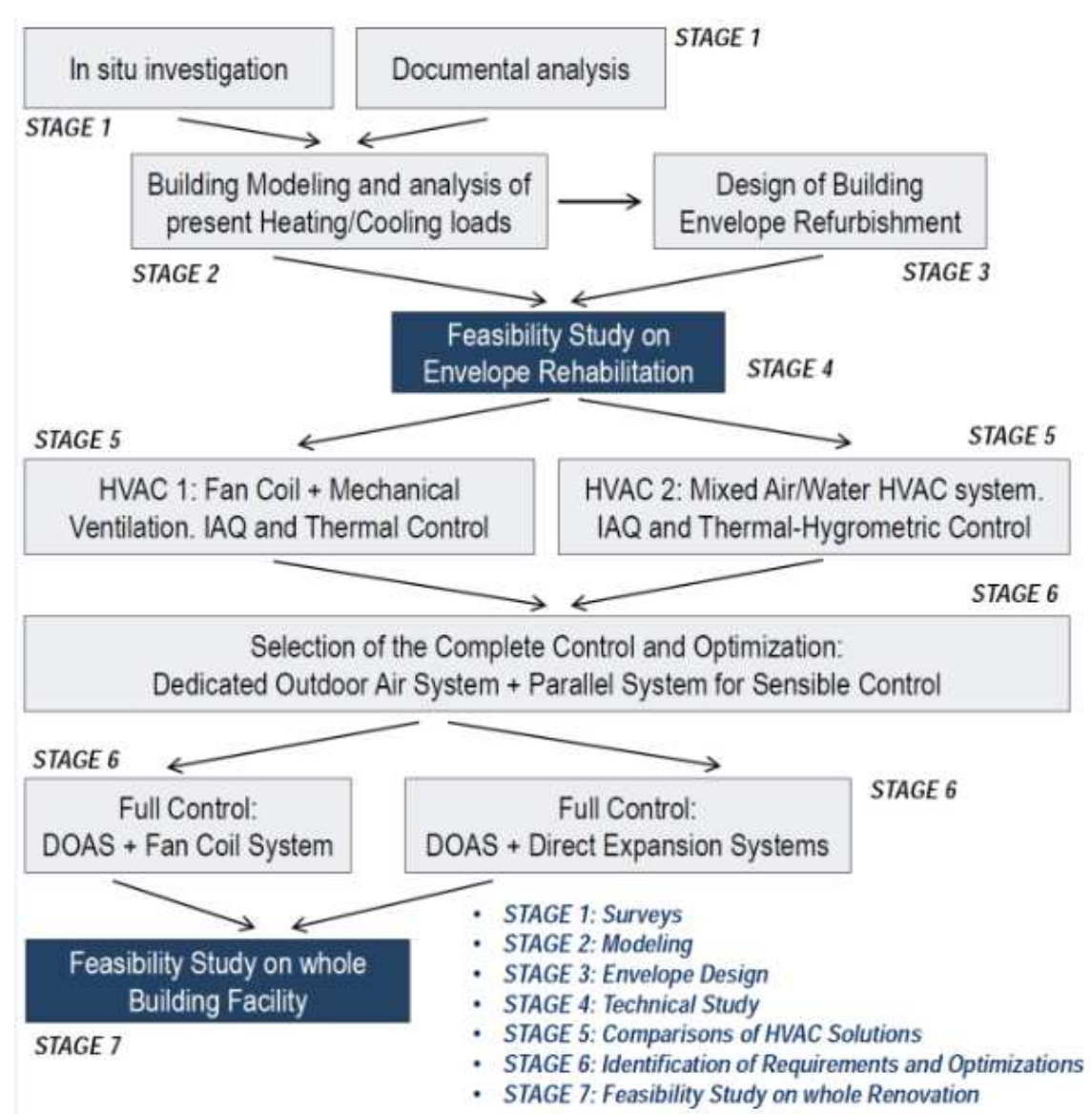

Fig. 2. Flow Chart of the carried out analyses

A first step (Stage 1) concerns the "in-field" surveys, aimed at identifying the weaknesses of the building envelope (Stage 2) in order to well design its energy refurbishment, in terms of added thermal resistance, thermal capacity and shading systems (Stage 3). Dynamic energy simulations have compared the energy performances of the base and refurbished buildings, by considering both heating and cooling periods. Simple feasibility studies have been then performed by assuming a base configuration of heating/cooling system, in order to evaluate the economical feasibility of the envelope refurbishment (Stage 4). Furthermore, a significant improvement of HVAC systems has been simulated. In particular, a base fan coil system with outdoor air handling and a mixed air/water HVAC system (obtained by combining fan coils and air handling units, without heat recovery, for the control of the latent loads and the indoor air quality) have been compared in terms of energy demands and microclimatic control (Stage 5). Furthermore, given the necessity of humidity control, this last system has been energy-optimized. Dedicated outdoor air systems, for the latent load control and the outdoor ventilation, have been coupled with various solutions for the sensible loads' balancing (and thus fan coils or, alternatively, direct expansion devices, based on the VRF technology). Set points for $\mathrm{T}$ and RH have been also diversified, by checking the specific necessities of each thermal zone. The main goal is a full indoor comfort without stressing the energy demand (Stage 6). Finally, a last feasibility study has been provided, aimed to orient the selection of the most proper HVAC system in terms of indoor control and operating costs (Stage 7):

The main original aspect of the paper is the underlining of the various heating/cooling loads of complex applications and thus the role played by the building envelope. Moreover, it is also evidenced how indoor temperature set-points, latent control and ventilation air affect the building energy performances with reference to health care facilities in Mediterranean climates. The understanding of such points can orient, successfully, the design process of Hospitals. 
Step-by-step, the entire process is shown in the following sections.

\section{Error Analysis of the Study Method (Experimental and/or Numerical)}

"Both small and full-scale validation studies have demonstrated that EnergyPlus results are well within the accuracy needed for building design (Olsen and Chen, 2003)". These words of Olsen and Chen well summarize a large literature dedicated to verify reliability of EnergyPlus (DOE, 2012) in predicting energy performances of building and active systems for the microclimatic control.

During the last years, several scientific papers investigated the reliability of EnergyPlus, with reference to the used format of weather data (Crawley et al., 2008), thermal envelope of the building (Ascione et al., 2011a; 2012; 2013b), systems and equipments for airconditioning (Shrestha and Maxwell, 2011; Zhou et al., 2008; Strand and Baumgartner, 2005), solar energy systems and renewable sources (Brent and Ellis, 2004; Rempela et al., 2013; Ascione et al., 2011b). Even if, sometime, some criticalities appear in the comparisons between modeled and measured data, a satisfactory reliability of the software is quite accepted by the scientific community. Moreover, the open source code allows continuous improvements of the program, even thanks to the participation of developers around the world in proposing and validating new models and calculation methodologies (Crawley et al., 2002; 2004). In particular, (Henninger and Witte, 2011a) compares energy evaluations, concerning the building thermal envelope (high and low mass, variable windows size and shadings), for more than 100 case studies, evidencing that EnergyPlus gives outcomes quite always in the same range of spread of other software for the whole building energy simulation. Also (Henninger and Witte, 2012) shows the reliable calculations of EnergyPlus compared to several other simulation software, all of these participating at the International Energy Agency project performed to test reliability of energy simulations of building.

Furthermore, according to the standard ANSI/ASHRAE 140-2011 (ANSI/ASHRAE, 2011) and the IEA HVAC BESTEST (Neymark and Judkoff, 2001), EnergyPlus was tested also with reference to the performances of HVAC equipments (Henninger and Witte, 2011b). In particular, with reference to many parameters connected to the active equipments performances, EnergyPlus gave average differences within a range of $1.1 \%$ compared to analytical calculations carried out according to tests implementing mathematical solutions for simple cases. This comparison refers to electric energy consumptions for fans, space cooling, direct expansion coils, coefficient of performances, overall cooling loads, sensible and latent cooling loads, mean indoor air temperature.

For the mean zone relative humidity ratio, the discrepancy was around $2.7 \%$, but only at high sensible heat ratio $(0.65 \%$ at low sensible heat ratio). Comparative tests for comparing EnergyPlus to other simulation programs have been reported also in (Henninger and Witte, 2015a) and (Henninger and Witte, 2015b), by Henninger and Witte for the U.S. Department of Energy.

In (Henninger and Witte, 2015a), for 20 different case studies, EnergyPlus was compared to other six software: Energy consumptions differ averagely by $2 \div 6 \%$. In (Henninger and Witte, 2015b) the outcomes of comparisons are even better, with average differences, compared to analytical solutions for predicting heat delivered to building zone, fuel required by boilers, energy demands for fans, very small and always lower than $\pm 1.1 \%$.

Other validation tests of EnergyPlus 7.2.0 have been carried out by comparisons with analytical tests, according to the ASHRAE 1052-RP Toolkit (Spitler et al., 2001), with reference to the building envelope components (Henninger and Witte, 2015c).

Moreover, specific validation reports have been developed for single phenomena of heat transfer, as for instance the heat transmission through slab on the ground, the interzonalconduction and radiation. In the first case, (Henninger and Witte, 2015d) carried out studies by means of comparisons with other simulation programs and with analytical procedures. EnergyPlus, with reference to the test-cases established by a specific IEA BESTEST (Neymark and Judkoff, 2008a), shows differences in the range $1.8 \div 21.8 \%$.

With reference to the interzonal heat transfer (Henninger and Witte, 2015e), the validation study compares EnergyPlus with other simulation programs, according to the case studies provided by IEA BestTest (Neymark and Judkoff, 2008b). These investigations showed a good correspondence in most cases. Moreover, in regards to specific HVAC components, (Henninger and Witte, 2015f) investigated the differences referred to the performances of chiller and hot water boiler simulated by EnergyPlus and catalog data by manufacturers. The component modeled in EnergyPlus are the same adopted by the authors of this paper and thus "Chiller:Electric:EIR" and "Boiler:HotWater". With reference to the refrigerator, the maximum gaps of the various developed tests were $0.12 \%$ for the cooling capacity, $0.77 \%$ for electric consumptions, $0.71 \%$ for COP. As regards the hot water boiler, the comparison was even better, with excellent correspondence. Furthermore, quite satisfactory comparisons have been developed also for chilled and hot water systems and coils (Henninger and Witte, 2015g). 
Finally, global energy balance tests were performed at various boundary volumes, for entire air-conditioning systems - direct expansion conditioners for windows and hydronic plants using several modules of the program (many of these used also in the simulative study here proposed)- in order to evaluate the accuracy of the calculation procedure. Even if some particular outcomes require further investigations and eventual corrections((Henninger and Witte, 2015h) for more details)- in most cases good or exact agreements have been found.

\begin{abstract}
Obviously, the quality of any energy simulation depends by the reliability of input data. With reference to the case study presented in this paper, various inputs have been derived by documental data and direct survey. With reference to building envelope, in order to properly define thermal-physical properties and geometry of the structures, analyses by heat flow meters and analytical calculation have been crossed.

The procedure will be discussed in the section 4.1 and section 4.2, with reference to the insitu measurement by heat flow meter and the error study about simulation parameters adopted for the proposed investigations, respectively.
\end{abstract}

\section{Discussion and Results}

\section{Stage 1: Surveys}

Documental materials, surveys and in-situ measurements have been carried out in order to define proper input data for the numerical modeling, by means of building simulation programs.

About the thermal transmittances $U\left[\mathrm{~W} / \mathrm{m}^{2} \mathrm{~K}\right]$, analytical calculations have been carried out according to the standard ISO EN 6946 (ISO, 2007), by using the well-known equation that operates the thermal resistance calculation by considering both "in series" and "inparallel" layers. In particular, several different compositions have been detected for the vertical opaque envelope, as described in the paragraph 2.The calculated thermal transmittance is equal to $1.30 \mathrm{~W} / \mathrm{m}^{2} \mathrm{~K}$ and this has been determined by averaging the areas of specific sections (areas above and below windows, undisturbed walls and structural frames in reinforced concrete). The average value of thermal transmittance takes into account also the effects of thermal bridge.

Moreover, heat flow meters have been installed on the opaque envelope, in order to determine- by experiments - the thermal conductance. Each monitoring followed the "Average Method ISO 9869" (ISO, 1994) and criticalities influencing the measurement have been avoided (for instance, by protecting the sensors with suitable boxes, for preventing alterations due to atmospheric agents). The output values, with reference to thermal conductance and heat flows, have been evaluated as reliable after a proper stabilization. The indoor temperature was quite constant during the $24 \mathrm{~h}$, i.e., around $22^{\circ} \mathrm{C}$, while the outdoor thermal levels had excursions around $12 \div 15^{\circ} \mathrm{C}$. However, after around $60 \mathrm{~h}$, the measured values went stable. Figure 3 shows the monitoring of the sub-window section of the wall. By averaging all measurement for all various sub-sections, a mean value for the thermal transmittance of vertical wall around $1.75 \mathrm{~W} / \mathrm{m}^{2} \mathrm{~K}$ was estimated. Thus, the difference between calculated and measured U UALUES was around $26 \%$. Really, the heterogeneity of the walls (pillars, beams, widening and reduction of thicknesses) induced bi- and three dimensional heat transfer effects.

Finally, the calculated value has been assumed for the modeling. Analogously, also for the other envelope structures - and thus ceiling, slabs on the ground and roofs - the assumed thermal transmittances are the ones calculated by means of the methodologies of the standard ISO EN 6946 (ISO, 2007).

\section{Stage 2: Modeling}

The achieved data, in terms of envelope thermophysics and geometry, have been used for the energy modeling of the building, under transient conditions. Several zones-with reference to the use, installed equipment, occupancy, lighting rate, set points for temperature and relative humidity-have been defined. Indeed, the building destination implies various quite different uses, for what concerns occupancy periods and required microclimatic conditions. Initially, geometry (Fig. 4) and zoning were assigned by means of Design Builder (DBSL, 2010). Then, a deeper model definition has been completed in EnergyPlus (Fig. 5), without using commercial interfaces, in order to have the highest flexibility, above all with reference to the definition of HVAC system. Weather data ASHRAE IWEC for Naples have been used.

In order to reduce computational time and to favor the convergence among energy balances of building and equipment, as well as for reducing the computational power required for the energy calculations, homogeneous and contiguous rooms have been grouped. The grouping has been carried out carefully, by considering uses of rooms, exposures and sources of gains and losses.

In most cases, the inputs have been defined considering the real operating conditions of "G. Pascale". In absence of information, profiles and schedules assumed by scientific literature or Italian Standard (e.g., Italian UNI 10339 (UNI, 1995)) were adopted.

According to standards EN 15603 (CEN, 2008a) and EN 13790 (CEN, 2008b), energy ratings of 
building can be "Asset", "Design" or "Tailored", according to various levels of detail. Obviously, the modeling of Day-Hospital building used information as much as possible precise, in order to have reliable outcomes. A model well-representative of the real problem, indeed, is the necessary base from which starting for investigation concerning potential of energy refurbishment (Ascione et al., 2010; Ma et al., 2012).

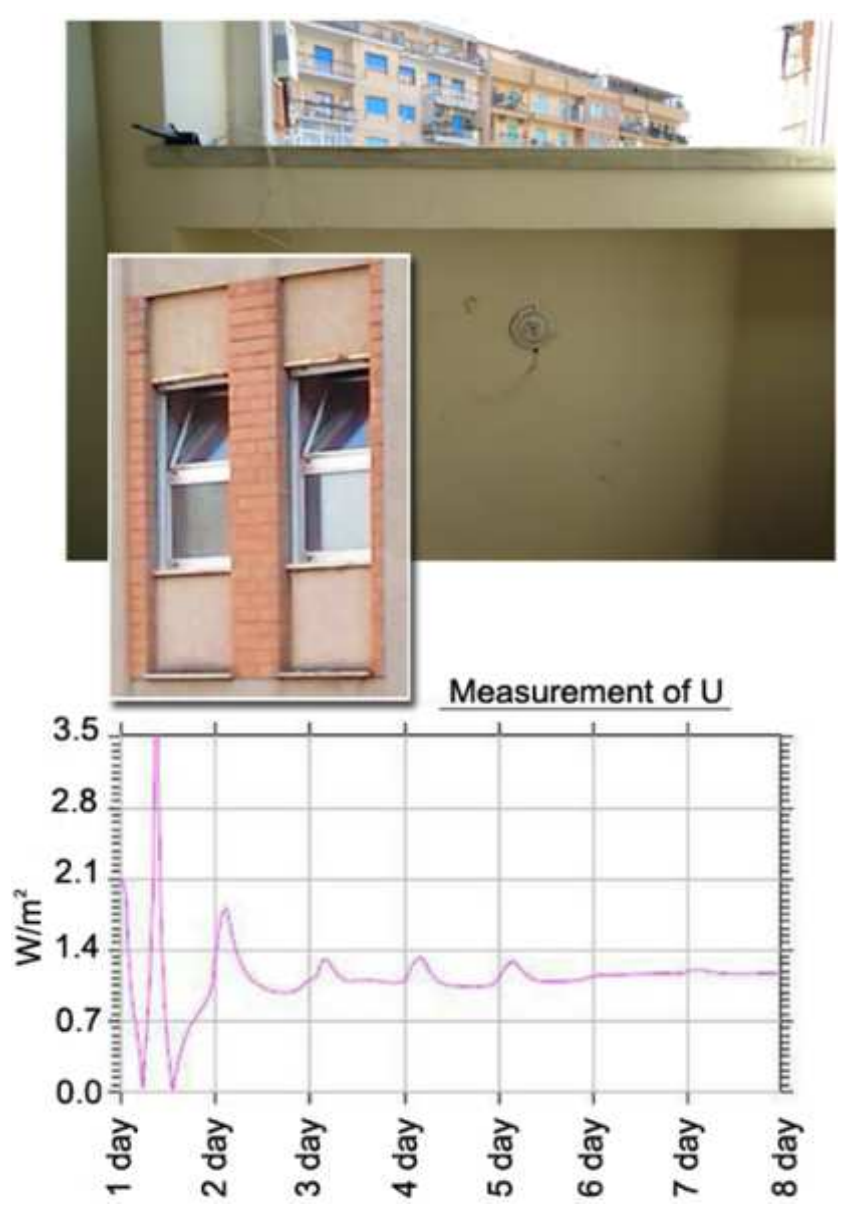

Fig. 3. Surveys on the building envelope
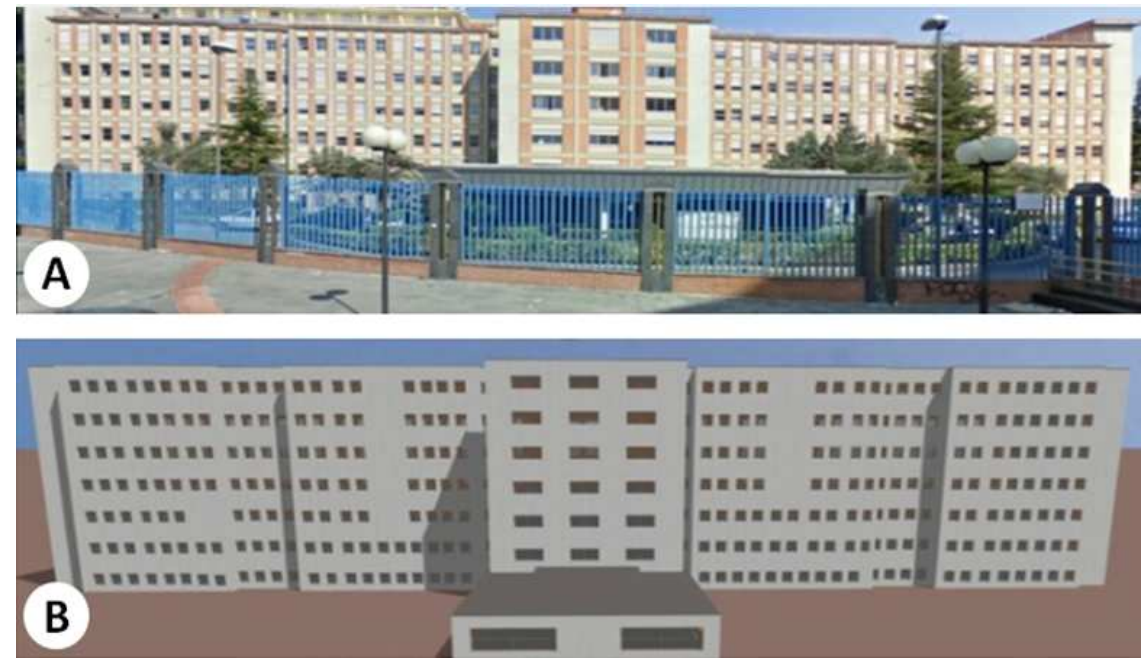

Fig. 4. Modeling of the Day-Hospital building 


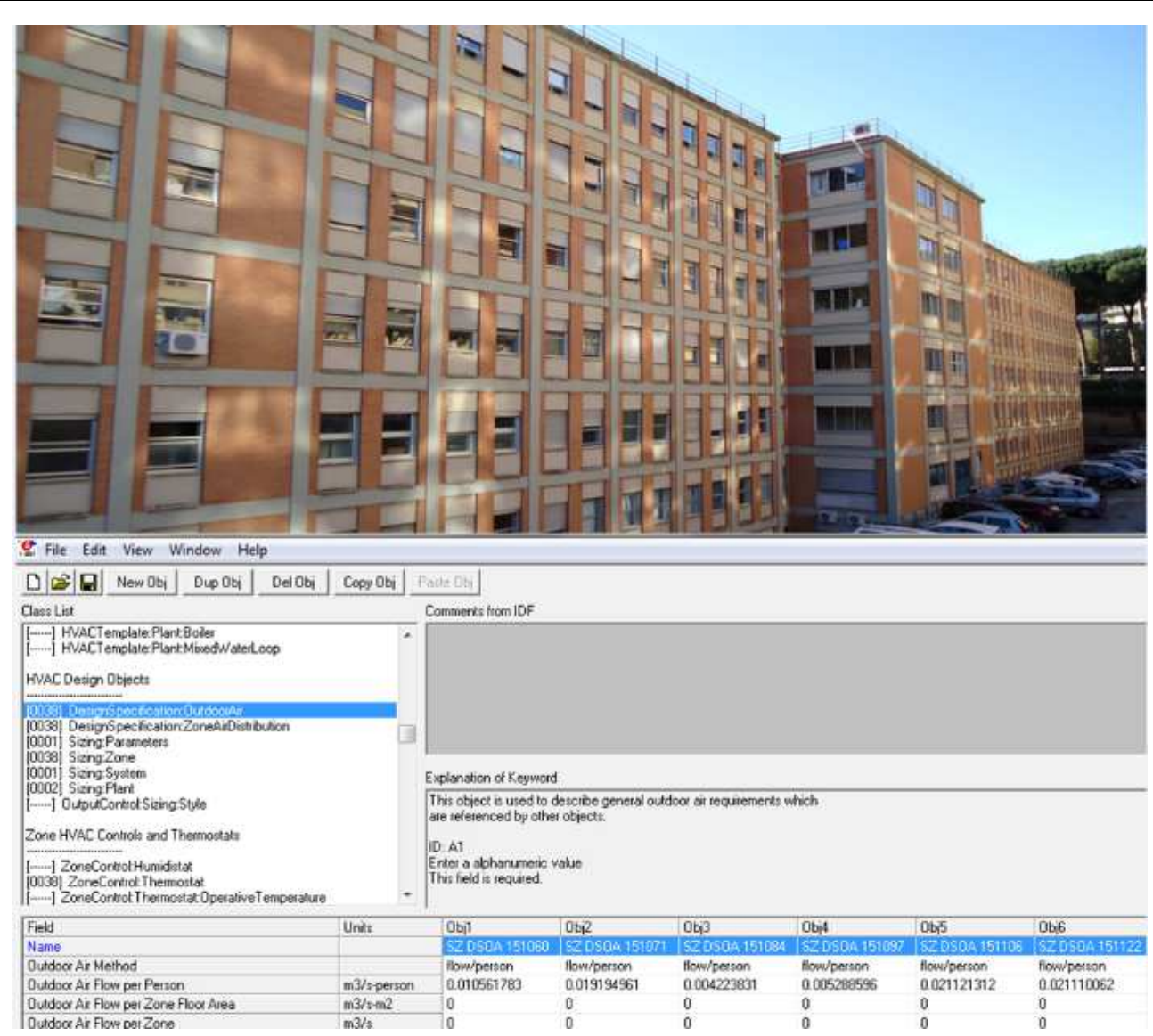

Fig. 5. Facade and definition of Input in EnergyPlus

As cited previously, the model defined multiple thermal zones, including hospital wards, immunology, cardiology, radiology studies, operating rooms, laboratories, cytopathology, nuclear medicine, clinical pathology, outpatient chemotherapy room, oncology, hematology, technical department and offices and so on.

The basic HVAC system, modeled in order to calculate energy requests, was a direct expansion heating/cooling plant, without outdoor air.

According to necessary verification concerning the error analyses, initially a wide investigation about the model reliability has been performed, in order to identify the right level of accuracy, without stressing the computational time. In particular, different algorithms for the resolution of the heat transfer and various time steps for the running of the simulations have been considered. More in detail, EnergyPlus can solve the transient heat transfer through the building according to several methodologies (and this is one of the most appreciated capability):

- Conduction Transfer Function algorithms (CTF)

- Conduction Finite Differences algorithms (ConFD)
- Combined Heat And Moisture Finite Element algorithms (HAMT)

CTF method is very powerful. Its formulation relates heat flux at one face of building element to the current and some of previous temperatures (at both inner and outer surfaces) and to the previous values of heat flows (DOE, 2012). The methodology has been largely studied and formulated, according to both the Laplace transform and anti-transform (previous generation of software) and to the "state space representation". Power and elegance of the state space representation is the neglecting, by means of the adoption of the matrix algebra, of the nodal temperatures. Finally, this approach does not require spatial discretization of walls and the thermal field through the envelope is not completely determined.

The method is fast and, in most case - above all for not very massive buildings- very accurate.

Finite Differences, conversely, solve completely the heat transfer through the building surfaces. The interior temperatures, at each node, are identified and calculated and this method has to be applied when the thermal field into the wall affects the building heat balance, as, for instance, in case of adoption of phase change materials 
and/or wall layers characterized by variable thermalphysical properties, such as thermal conductivity. Compared to CTF methodology, the method of finite differences is much more time-consuming and heavy under the computational point of view.

The last one and thus the "Combined heat and moisture finite Element algorithm", solves onedimensional heat flows through the building components by considering contemporarily vapor and heat transfers. Transportation and storage of moisture and thermal energy are solved simultaneously, by allowing fully developed profiles of inner temperatures and dew points. This allows identification of, for instance, risks of mould and interstitial condensations. The method should be applied only for particular studies.

The described methods are characterized, as said, by very different computational times. Moreover, also the "Number of time-steps per hour" (representing the time interval between consecutive energy balances) strongly affects simulation time and reliability. Usually, values between 1 time step/hour and 60 time steps/hour are used. As suggested by the developers of EnergyPlus, 60 time steps/hour "should only be used in rare occasions" (DOE, 2012). Finally, in the following lines, a study about the best compromise between method reliability and computational time is presented. According to common optimization studies, the following tests have been performed, with reference to the base building and HVAC system:

- Conduction Transfer Function with 2 time-steps/hour

- Conduction Transfer Function with 4 time-steps/hour

- Conduction Transfer Function with 8 time-steps/hour

- Conduction Transfer Function with 10 time-steps/hour

- Conduction Transfer Function with 20 time-steps/hour

- Conduction Finite Difference with 20 time-steps/hour

With reference to the required computational time, the values are reported in Table 2 and these concern the use of a personal computer characterized by the following characteristics: Intel Core i7 $1.73 \mathrm{GHz}, 64$ bit, Ram: 6 GB, Operating System Windows 7 Home Premium.

In Fig. 6, with reference to each energy use related to air-conditioning, the annual errors compared to the most accurate method have been reported.

Percentage error on varying simulation parameters compared to Conduction Finite Differences with 20 time-steps/hour

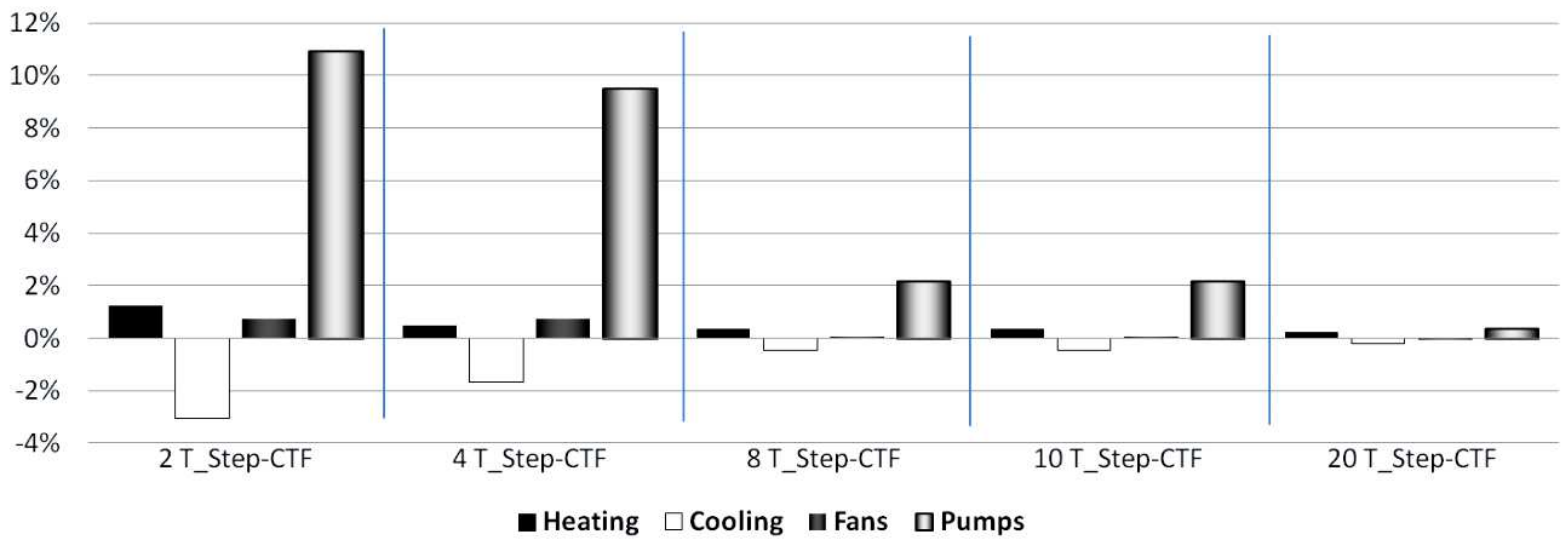

Fig. 6. Error analysis on varying simulation time-steps of "conduction transfer functions" compared to conduction finite differences algorithms

Table 2. Computational times and error analysis with reference to heat transfer solution algorithms and simulation time-steps

\begin{tabular}{|c|c|c|c|c|c|c|}
\hline Elapsed & 2 time-steps & 4 time-steps & 8 time-steps & 10 time-steps & 20 time-steps & 20 time-steps \\
\hline \multirow{4}{*}{ Computational time } & CTF & CTF & CTF & CTF & CTF & Finite Differences \\
\hline & $00 \mathrm{hr}$ & $00 \mathrm{hr}$ & $00 \mathrm{hr}$ & $00 \mathrm{hr}$ & $00 \mathrm{hr}$ & $09 \mathrm{hr}$ \\
\hline & $06 \mathrm{~min}$ & $10 \mathrm{~min}$ & $20 \mathrm{~min}$ & $21 \mathrm{~min}$ & $39 \mathrm{~min}$ & $49 \min$ \\
\hline & $19.07 \mathrm{sec}$ & $5.01 \mathrm{sec}$ & $03.58 \mathrm{sec}$ & $31.14 \mathrm{sec}$ & $11.53 \mathrm{sec}$ & $45.48 \mathrm{sec}$ \\
\hline \multicolumn{7}{|c|}{ Percentage Error, for each energy use, compared to "20 time-steps Finite Differences" } \\
\hline Heating & $1.22 \%$ & $0.47 \%$ & $0.35 \%$ & $0.35 \%$ & $0.22 \%$ & ----- \\
\hline Cooling & $-3.06 \%$ & $-1.69 \%$ & $-0.47 \%$ & $-0.47 \%$ & $-0.20 \%$ & ----- \\
\hline Fans & $0.75 \%$ & $0.75 \%$ & $0.09 \%$ & $0.09 \%$ & $-0.01 \%$ & ----- \\
\hline Pumps & $10.93 \%$ & $9.50 \%$ & $2.15 \%$ & $2.15 \%$ & $0.35 \%$ & ----- \\
\hline Overall primary energy requests & $0.6454 \%$ & $0.4449 \%$ & $0.2171 \%$ & $0.2171 \%$ & $0.0993 \%$ & ----- \\
\hline
\end{tabular}


Table 3. Thermal loads and energy requests for $\mathrm{A} / \mathrm{C}$ of the present building

Present building loads and needs

\begin{tabular}{ll}
\hline Heating Peak $(\mathrm{kW})$ & $1242\left(\rightarrow 121 \mathrm{~W} / \mathrm{m}^{2}\right)$ \\
Cooling Peak $(\mathrm{kW})$ & $522\left(\rightarrow 51 \mathrm{~W} / \mathrm{m}^{2}\right)$ \\
Primary Energy for Heating $\left(\mathrm{kWh} / \mathrm{m}^{2}\right)$ & 73.8 \\
Primary Energy for Cooling $\left(\mathrm{kWh} / \mathrm{m}^{2}\right)$ & 30.0 \\
Primary Energy for Fans $\left(\mathrm{kWh} / \mathrm{m}^{2}\right)$ & 11.1 \\
Primary Energy for Pumps $\left(\mathrm{kWh} / \mathrm{m}^{2}\right)$ & 6.5 \\
Total Primary Energy for HVAC $\left(\mathrm{kWh} / \mathrm{m}^{2}\right)$ & 121.4 \\
\hline
\end{tabular}

It is quite evident that Conduction Transfer Functions with 20 time steps are completely reliable, with an average error, in the calculation of primary energy required for the annual air-conditioning, lower than $0.0995 \%$ compared to the Finite Difference methods and the computational time is around 15 times lower (2'351.53 seconds vs. 35'385.48 seconds). Therefore, in the following studies, CTFs at 20 timesteps have been adopted.

Table 3 shows heating and cooling peak loads and annual thermal needs. This phase neglects the ventilation loads, in order to singularly underline the role of the building envelope. Therefore, only the convective heat transfer due to infiltration has been considered and thus the thermal losses due to the poor air tightness of the building $(\rightarrow 0.3 \mathrm{ACH})$ and a small amount of natural ventilation because of the opening of windows and door $(\rightarrow 0.7 \mathrm{ACH})$.

As visible in Table 3, the highest energy demand is due to the space heating. This outcome is confirmed both by peak loads and by annual energy demands.

\section{Stage 3: Refurbishment of the Building Envelope}

The analysis of energy outcomes, for what concerns the heating and cooling demands of the base building (i.e., before the energy renovation), immediately suggested a deep refurbishment of the building envelope. Ascione et al. (2013) showed that the role of building envelope is not marginal in health care applications, even if the ventilation loads are preponderant. Indeed, some hospital uses are similar to applications of tertiary sector (offices, administration rooms, warehouses, some ambulatories). Moreover, the improvement of the building envelope, in terms of thermal resistance and thermal capacity, improves also the indoor microclimatic stability.

With reference to the case study here presented, by analyzing accurately the causes of winter heat losses and summer heat gains, the actions on the building envelope represented in Fig. 7 have been designed and computed.

An external insulation with panels of Extruded Polystyrene (XPS) has been designed for the vertical frame of beams and pillars, because these are significant thermal bridges. Moreover, insulation sheets of XPS have been installed on the internal face of the walls above and below the windows, by installing also a proper vapor barrier. Moreover, the air gap between two layers of hollow blocks has been filled, by injection of perlite. All told, three different retrofit measures have been designed for the vertical facade; at the boundaries, the insulation layers have been overlapped in order to reduce the thermal bridging effect. With reference to windows systems, these have been replaced with ones more efficient, characterized by wood frame, thermal breaking and transparent parts in double layers of glass with argon filling. External aluminum blinds have been designed for the solar protection in summer.

The roof structure has been refurbished by installing $10 \mathrm{~cm}$ of XPS on the outer surface, with a proper waterproofing layer. No retrofit measures have been designed for the slab on the ground, because of technological difficulties and in order to favor, without insulation, heat dissipations during the cooling season.

Definitively, the thermal transmittances of the building envelope have varied as shown:

- Vertical walls: $U_{\text {VALUE }}=0.34 \mathrm{~W} / \mathrm{m}^{2} \mathrm{~K}$

- Roof structure: $\mathrm{U}_{\mathrm{VALUE}}=0.35 \mathrm{~W} / \mathrm{m}^{2} \mathrm{~K}$

- Windows (average value of glazing and frame): $\mathrm{U}_{\mathrm{VALUE}}=1.95 \mathrm{~W} / \mathrm{m}^{2} \mathrm{~K}$

In the next section, the energy performances of base (Table 3) and refurbished (Table 4) buildings are compared.

\section{Stage 4: Feasibility Study}

The comparison of Table 3 and 4 induces the following conclusions:

- The retrofit of building envelope reduces the energy demand for space heating around $62.0 \%$. This outcome is quite significant and derives by the increase of thermal resistance of building envelope and because of reduction of the infiltrations due to the improved airtightness

- The cooling primary energy demand is reduced of $27.9 \%$. This depends mainly by installation of shading systems, with a control strategies based on the incident solar radiation. The improvement of the airtightness, with reference to the entire cooling season, is slightly penalizing 
- $\quad$ Energy demand of auxiliaries decreases of $41.1 \%$. Lower thermal/cooling demands imply, indeed, a lower use of air and water loops, in terms of on/off cycles and part-load operations

Finally, even if ventilation is not yet considered, the improving of building envelope allows, globally, reduction of the annual primary energy demand for annual airconditioning around 2252 GJ. Definitively, the specific demand decreases from 121.4 to $60.0 \mathrm{kWh} / \mathrm{m}^{2}$.

The costs of renovation have been accurately estimated. The total amount with reference to the rehabilitation of building envelope, is $€ 1^{\prime} 200 ' 556$, including scaffolding and security charges.

The costs of natural gas and electricity cited by the EU for Italy- and thus 0.25 and $0.07 € / \mathrm{kWh}_{\mathrm{GAS}^{-}}$have been considered. A simple payback period around
25.1 years has been calculated; this is completely feasible by considering the lifetime of applied measures ((Ascione et al., 2013) infers coherent outcomes, for the same building equipped with other HVAC systems). Moreover, as shown in the following sections, the building envelope refurbishment implies also improvement of indoor comfort.

\section{Stage 5: HVAC Solutions, with or Without Control of Relative Humidity}

Until now, the study has been focused only on the building envelope. Really, as known, health care facilities require a high air quality control and thus large outdoor ventilation. This section compares the energy performances of the refurbished buildings, on varying the kind of HVAC system (Fig. 8):

Table 4. Thermal loads and energy requests for $\mathrm{A} / \mathrm{C}$ of the building with refurbished envelope

\begin{tabular}{lc}
\hline Refurbished building loads and needs & $768\left(\rightarrow 75 \mathrm{~W} / \mathrm{m}^{2}\right)$ \\
\hline Heating Peak $(\mathrm{kW})$ & $303\left(\rightarrow 30 \mathrm{~W} / \mathrm{m}^{2}\right)$ \\
Cooling Peak $(\mathrm{kW})$ & 28.0 \\
Primary Energy for Heating $\left(\mathrm{kWh} / \mathrm{m}^{2}\right)$ & 21.6 \\
Primary Energy for Cooling $\left(\mathrm{kWh} / \mathrm{m}^{2}\right)$ & 6.5 \\
Primary Energy for Fans $\left(\mathrm{kWh} / \mathrm{m}^{2}\right)$ & 3.9 \\
Primary Energy for Pumps $\left(\mathrm{kWh} / \mathrm{m}^{2}\right)$ & 60.0 \\
Total Primary Energy for HVAC $\left(\mathrm{kWh} / \mathrm{m}^{2}\right)$ & \\
\hline
\end{tabular}

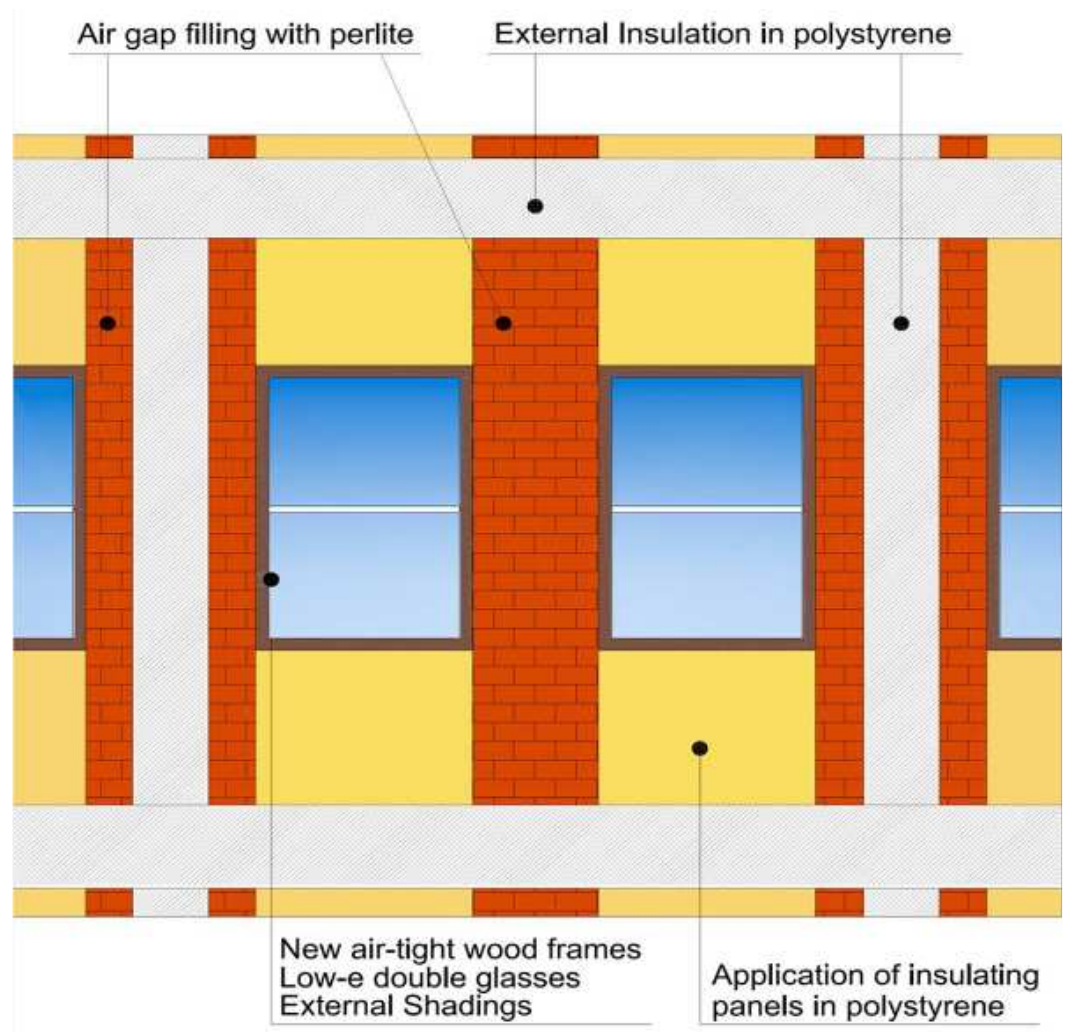

Fig. 7. Retrofit of the building envelope 


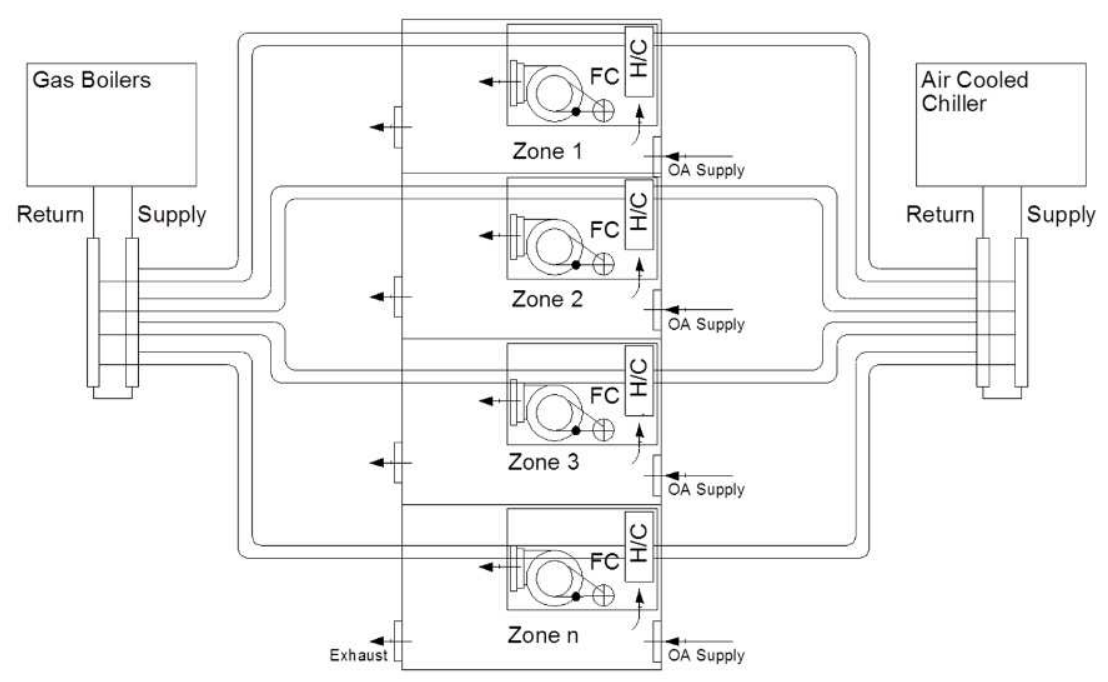

(a)

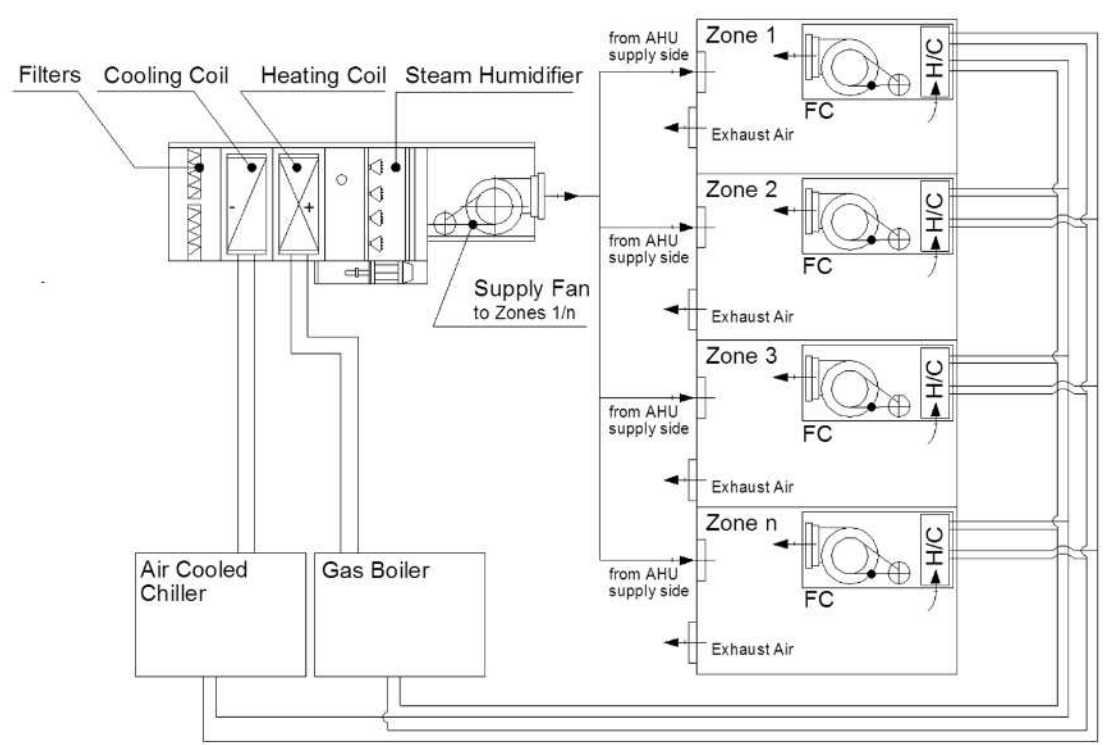

(b)

Fig. 8. Systems' layout: (a) Fan Coil + mechanical ventilation, (b) Multizone mixed air/water system

HVAC system (n.1) combines mechanical ventilation and control of sensible loads for the space heating and cooling. In particular, fan coils operate by mixing outdoor and recirculation airs. The amount of OA largely varies depending on thermal zone destination (e.g., 2.5 ACH for wards and ambulatories, 2.0 ACH for entrance and corridors, 1.0 $\mathrm{ACH}$ for stairs and warehouses, etc.). With reference to health care facilities, as known, the ventilation is the main cause of the intensive energy demand for airconditioning (Rempela et al., 2013).

HVAC system (n. 2) combines fan coils to an allair system without recirculation, for the latent loads' control and the zone ventilation. With reference to all zones, the setpoint of relative humidity is $45 \%$ in winter, 55\% in summer. Air Handling Units are not provided with heat recovery systems.

In Table 5, the achieved energy performancesevaluated by simulations with EnergyPlus- are compared. The humidity control is quite problematic when several air changes of outdoor air are necessary. This happens mainly during the cooling season. The large amount of outdoor air, indeed, implies an expensive sub-cooling (in order to condense the excessive air moisture) and then a large re-heating process. The high ventilation, even if contributes to guarantee an optimal IAQ, is very disadvantageous under the energy point of view, because of the necessary processes of sub-cooling and re-heating. 
Definitively, the latent load control- in all thermal zones-coupled to the large OA ventilation, induces requests, in terms of primary energy demand for the annual microclimatic control, 2.73 times higher (i.e., $511.7 \mathrm{kWh} / \mathrm{m}^{2}$ vs. $187.3 \mathrm{kWh} / \mathrm{m}^{2}$ ) compared to the energy demands of an air-conditioning for the mere control of IAQ and sensible loads.

Really, even if health care facilities require stringent thermal-hygrometric controls, in many zones it is not necessary a full control of relative humidity (for instance, in warehouses, toilets and stairs and so on). However, everywhere humidity conditions should guarantee healthiness of people and architecture (Bellia and Minichiello, 2003), by avoiding, for instance in winter, vapor condensations or mould growth.

Analogously, even if contamination between supply air and exhaust air flows must be absolutely avoided, in some departments the heat recovery can be allowed, without any contact, direct or not, between the air fluxes, e.g., by adopting flat plate heat recovery. Therefore, in the following analysis, the HVAC system was optimized:

- By varying set-points for indoor temperature, by choosing the less critical of the comfort range

- By distinguishing the thermal zones that require or not the relative humidity control

- By designing adoption of heat recovery system, when possible, in order to allow sensible exchange between supply and exhaust flows

Please, note that the latent heat is not recovered, because it would require a contact (even if "indirect") between supply and exhaust airflows. This is not admitted for health care facilities.
Stage 6: Identification of Requirements and Optimization of HVAC System

The section is aimed to optimize the microclimatic control, allowing, for each specific thermal zone, the required indoor conditions and air quality, without stressing relative humidity control if not necessary.

A dedicated outdoor air system, equipped with a plate sensible heat recovery and designed for the latent control $\left(\mathrm{RH}_{\text {SETPOINT}}\right.$ : winter $45 \%$, summer $55 \%$ ), is coupled to:

- A water system for the sensible control, with inroom fan coils

- A direct expansion VRF system, with in-room coils for the local heating and cooling

The systems are shown in Fig. 9. Also the temperature set-points have been diversified for each zone, according to three categories:

- $\quad$ High control: $\mathrm{T}_{\text {WINTER }}=22^{\circ} \mathrm{C} ; \mathrm{T}_{\text {SUMMER }}=26^{\circ} \mathrm{C}$

- Medium control: $\mathrm{T}_{\text {WINTER }}=21^{\circ} \mathrm{C} ; \mathrm{T}_{\text {SUMMER }}=26^{\circ} \mathrm{C}$

- Low control: $\mathrm{T}_{\text {WINTER }}=20^{\circ} \mathrm{C} ; \mathrm{T}_{\text {SUMMER }}=26^{\circ} \mathrm{C}$

Setback temperatures, during the nocturnal operation, vary according to the specific necessities.

Building energy simulations, carried out by Energy Plus 7.2.0, infer the outcomes shown in Table 6. The combining of DOAS and VRF (instead of DOAS and fan coils) is advantageous, at least with reference to the specific boundary conditions. In this way, energy requests for the pumping of hot/cold waters are nullified. Energy demands for fans are similar. Globally, the more efficient DX coils induce significant savings also for the space heating and cooling.

Table 5. Thermal loads and energy requests for $\mathrm{A} / \mathrm{C}$ of the refurbished building on varying the HVAC

\begin{tabular}{|c|c|c|c|}
\hline & $\begin{array}{l}\text { FC with mechanical } \\
\text { ventilation }\end{array}$ & $\begin{array}{l}\text { Mixed } \\
\text { Air / Water system }\end{array}$ & $\Delta \mathrm{E}$ \\
\hline Heating $\left(\mathrm{GJ}_{\text {PRIMARY }}\right)$ & 4503 & 8946 & $99 \%$ \\
\hline Cooling (GJ PRIMARY $)$ & 1704 & 6592 & $287 \%$ \\
\hline Fans $\left(\mathrm{GJ}_{\text {PRIMARY }}\right)$ & 173 & 2134 & $1131 \%$ \\
\hline Pumps (GJ & 355 & 881 & $148 \%$ \\
\hline Humidification ( $\left.\mathrm{GJ}_{\text {PRIMARY }}\right)$ & 0 & 268 & --- \\
\hline Total $\left(\mathrm{GJ}_{\text {PRIMARY }}\right)$ & 6735 & 18821 & $179 \%$ \\
\hline Total $\left(\mathrm{kWh}\right.$ PRIMARY $\left./ \mathrm{m}^{2}\right)$ & 183.6 & 512.9 & $179 \%$ \\
\hline
\end{tabular}

Table 6. Comparison of energy requests, by coupling the DOAS system to Fan Coils or VRF

\begin{tabular}{llll}
\hline & DOAS + Fan Coils & DOAS + Direct Expansion & $\Delta \mathrm{E}$ \\
\hline Heating $\left(\mathrm{GJ}_{\text {PRIMARY }}\right)$ & 3624.6 & 2827.2 & $-22 \%$ \\
Cooling $\left(\mathrm{GJ}_{\text {PRIMARY }}\right)$ & 2497.7 & 1756.1 & $-30 \%$ \\
Fans $\left(\mathrm{GJ}_{\text {PRIMARY }}\right)$ & 1040.6 & 1133.2 & $+9 \%$ \\
Pumps $(\mathrm{GJ} \mathrm{JPRIARY})$ & 283.8 & 0.0 & $-100 \%$ \\
Humidification $(\mathrm{GJ}$ & 51.4 & 51.4 & \\
Total $\left(\mathrm{GJ}_{\text {PRIMARY }}\right)$ & 7498.1 & 5767.8 & $-23 \%$ \\
Total $\left(\mathrm{kWh} \mathrm{k}_{\text {PRIMARY }} / \mathrm{m}^{2}\right)$ & 204.3 & 157.2 & $-23 \%$ \\
\hline
\end{tabular}




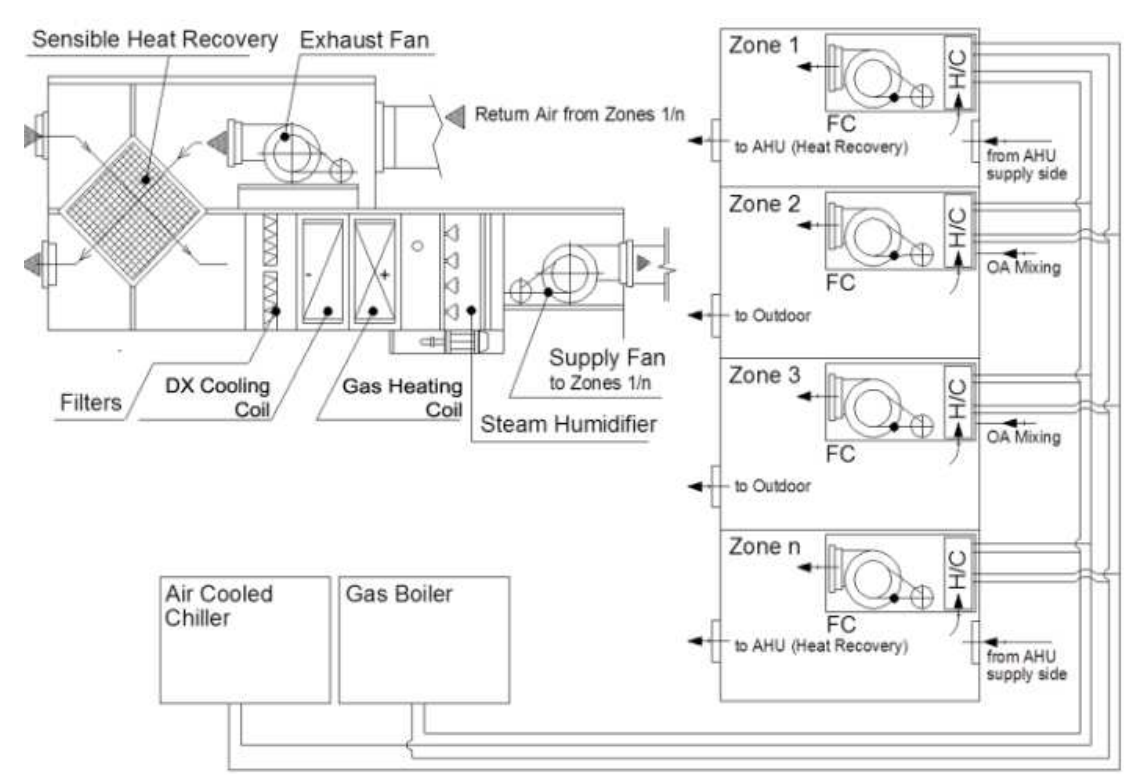

(a)

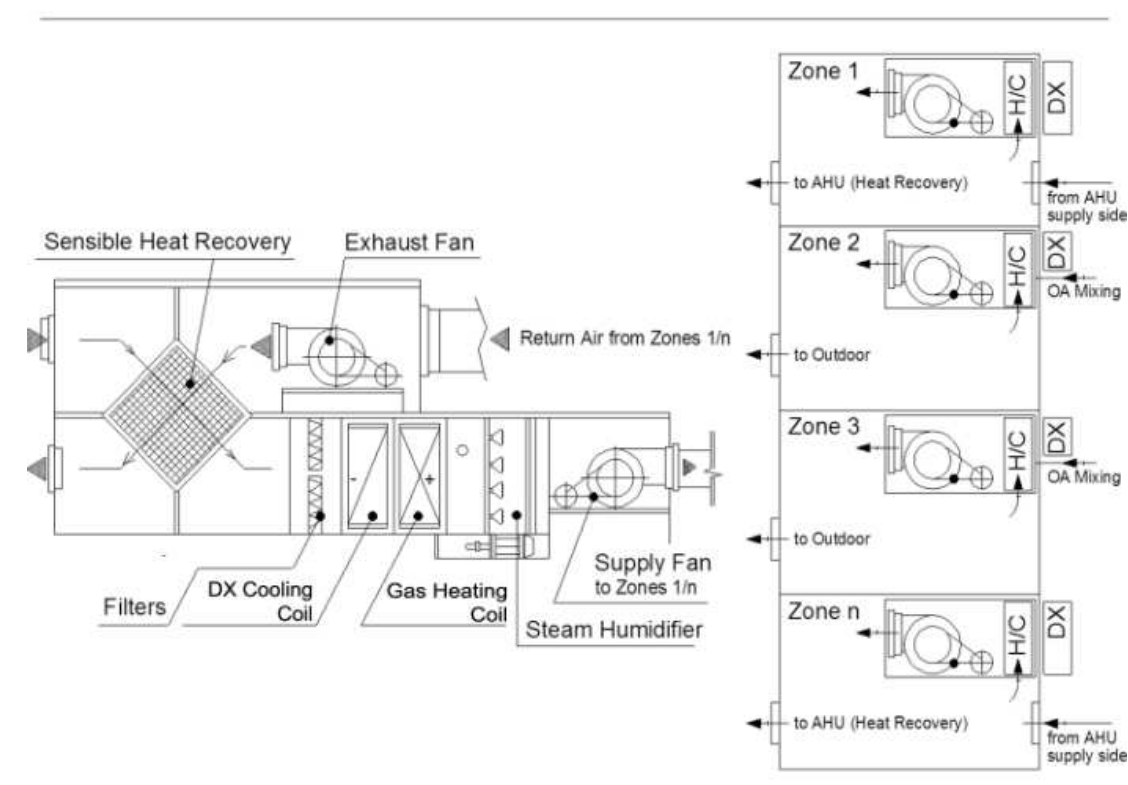

(b)

Fig. 9. Systems' layout: (a) DOAS + Fan Coils, (b) DOAS + Direct Expansion Coils

All told, the splitting of systems (one for the latent control and the IAQ necessities, the other one for the sensible handling) and the diversification of indoor set points induce significant energy savings compared to a traditional air-water system. This result is due to:

- High efficiency of DX systems

- Adoption of heat recovery

- Diversification of microclimatic control, without a generalized strict microclimate for both temperature and relative humidity (Table 6) in all zones, as shown at the Stage 5
Definitively, the optimization of HVAC system and thermal-hygrometric control imply, with reference to the enire health care facility, an overall energy demand for air-conditioning and ventilation equal to $157.2 \mathrm{kWh} / \mathrm{m}^{2}$.

In Fig. 10 and 11, the building performances are analyzed respectively for typical winter and summer days, with reference to indoor temperature (upper graphs) and relative humidity (down graphs). In particular, three thermal zones are studied, each one characterized by a different required level of control. The two HVAC systems induce quite the same indoor microclimate. 

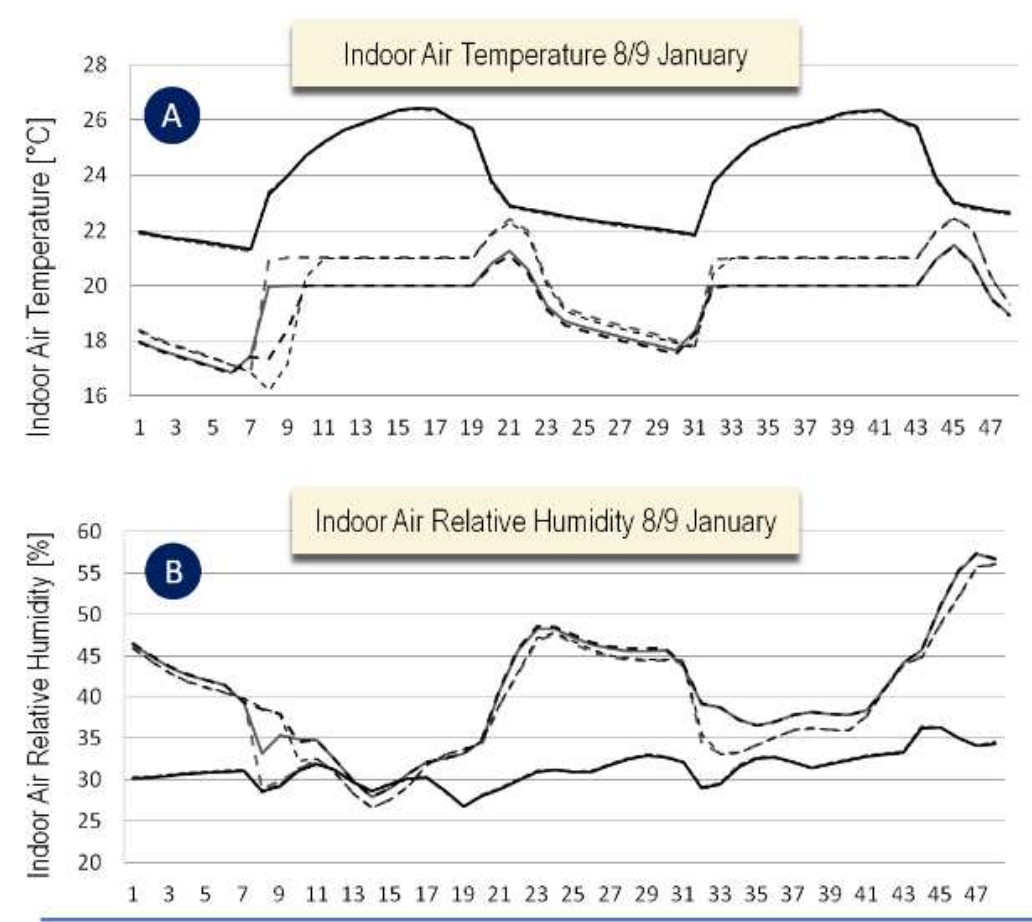

-FC-Low-Control ----FC-Med-Control --.--FC-High-Control ---DX-Low-Control -..- DX-Med-Control-DX-High-Control

Fig. 10. T and RH control in two winter days (heating season)
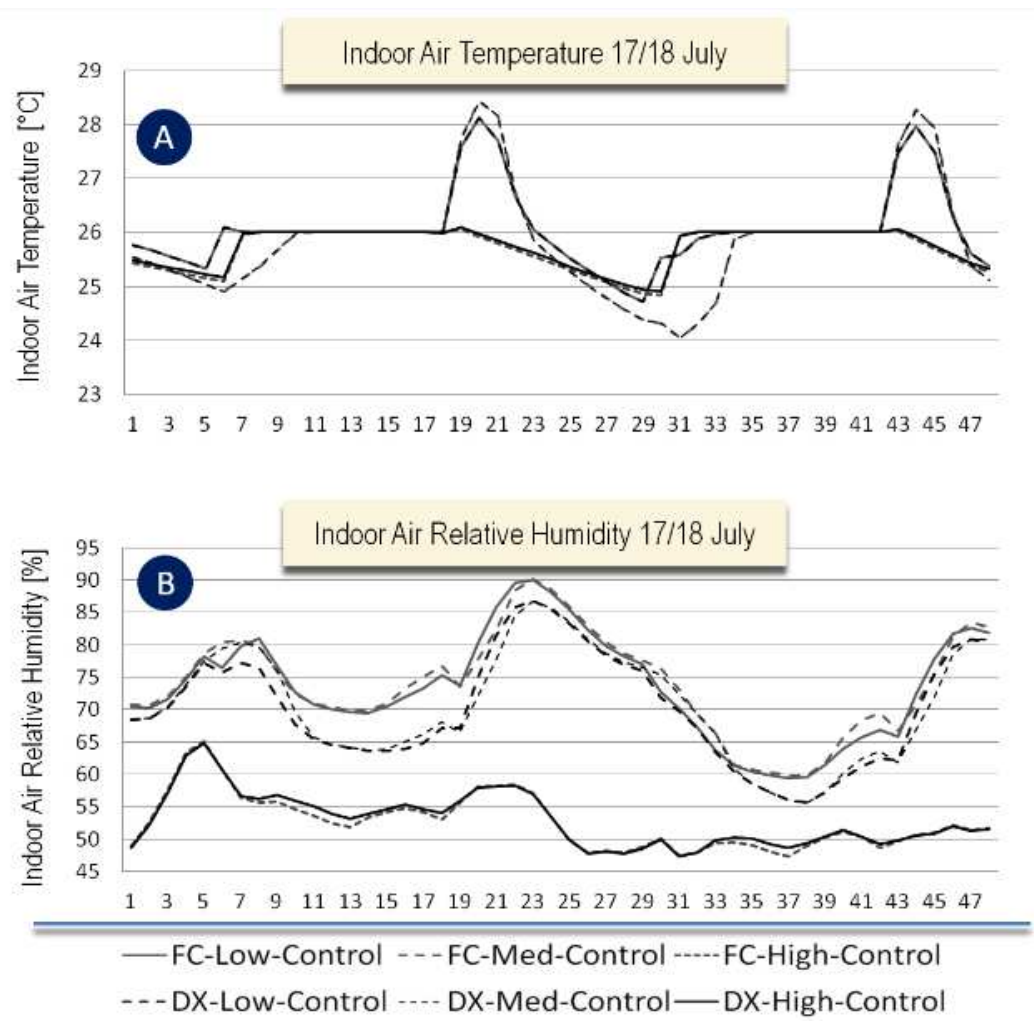

Fig. 11. T and RH control in two summer days (cooling season) 
Also an analysis extended to the whole year reveals very similar performances. An index already introduced by (Ascione et al., 2009; Ascione and Minichiello, 2010) has been here used in order to evaluate the seasonal control i.e., the Performance Index for temperature and relative humidity (" $\mathrm{PI}_{\mathrm{T}}$ " and $" \mathrm{PI}_{\mathrm{RH}}$ " in the next lines). These indexes are the time percentage, for the heating or cooling periods, characterized by indoor conditions within the comfort range:

- Low control zones: In winter, indoor temperatures are comfortable if are in the range $18 \div 24^{\circ} \mathrm{C}$, while the relative humidity should be between $35 \div 65 \%$. In summer, temperatures in the range $23 \div 29^{\circ} \mathrm{C}$ and relative humidity between $35 \div 65 \%$ are needed

- Medium control zones: In winter, indoor temperatures are comfortable if are in the range $19 \div 23.5^{\circ} \mathrm{C}$, while the relative humidity should be between $35 \div 65 \%$. In summer, temperatures in the range $24 \div 28^{\circ} \mathrm{C}$ and relative humidity between $35 \div 65 \%$ are needed
- High control zones: In winter, indoor temperatures are comfortable if are in the range $21 \div 23.5^{\circ} \mathrm{C}$, while the relative humidity should be between $35 \div 55 \%$. In summer, temperatures in the range $24 \div 27^{\circ} \mathrm{C}$ and relative humidity between $45 \div 65 \%$ are needed

The $\mathrm{PI}_{\mathrm{T}}$ and $\mathrm{PI}_{\mathrm{RH}}$ reported in Fig. 12 and Table 7 have been calculated. On varying the HVAC system, quite equivalent performances are shown for both indoor air temperatures and relative humidity, during the heating and cooling periods.

\section{Stage 7: Feasibility Study Referred to the Whole Renovation}

This last section investigates the economical feasibility of combining DOAS and VRF, compared to DOAS + fan coils. The following costs have been calculated:

- $\quad$ DOAS + Fan Coils = 1'076'336€

- $\mathrm{DOAS}+\mathrm{VRF}=1^{\prime} 177^{\prime} 243 €$
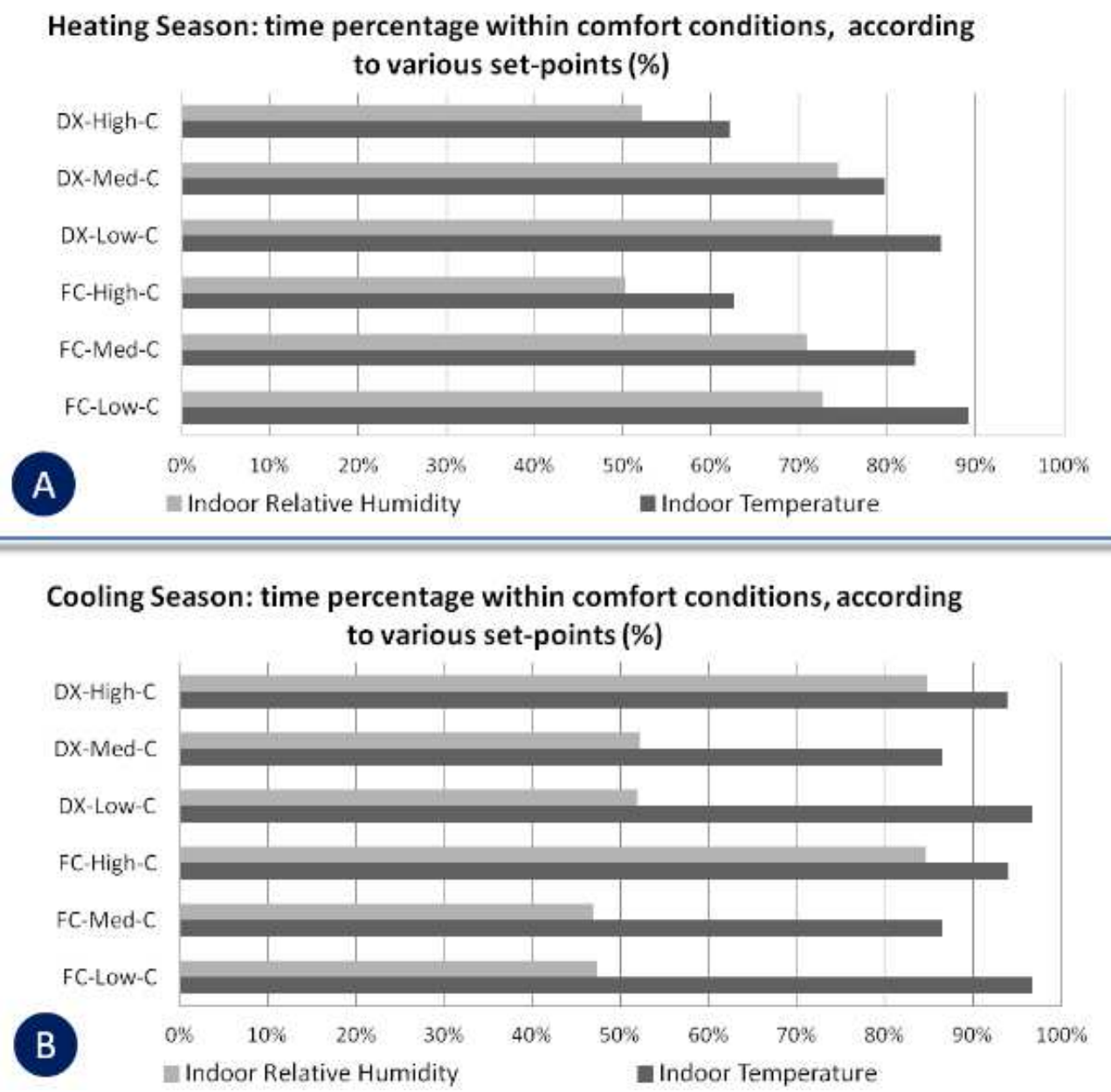

Fig. 12. Performance index of temperature and relative humidity on varying the HVAC, in winter (A) and summer (B) times 


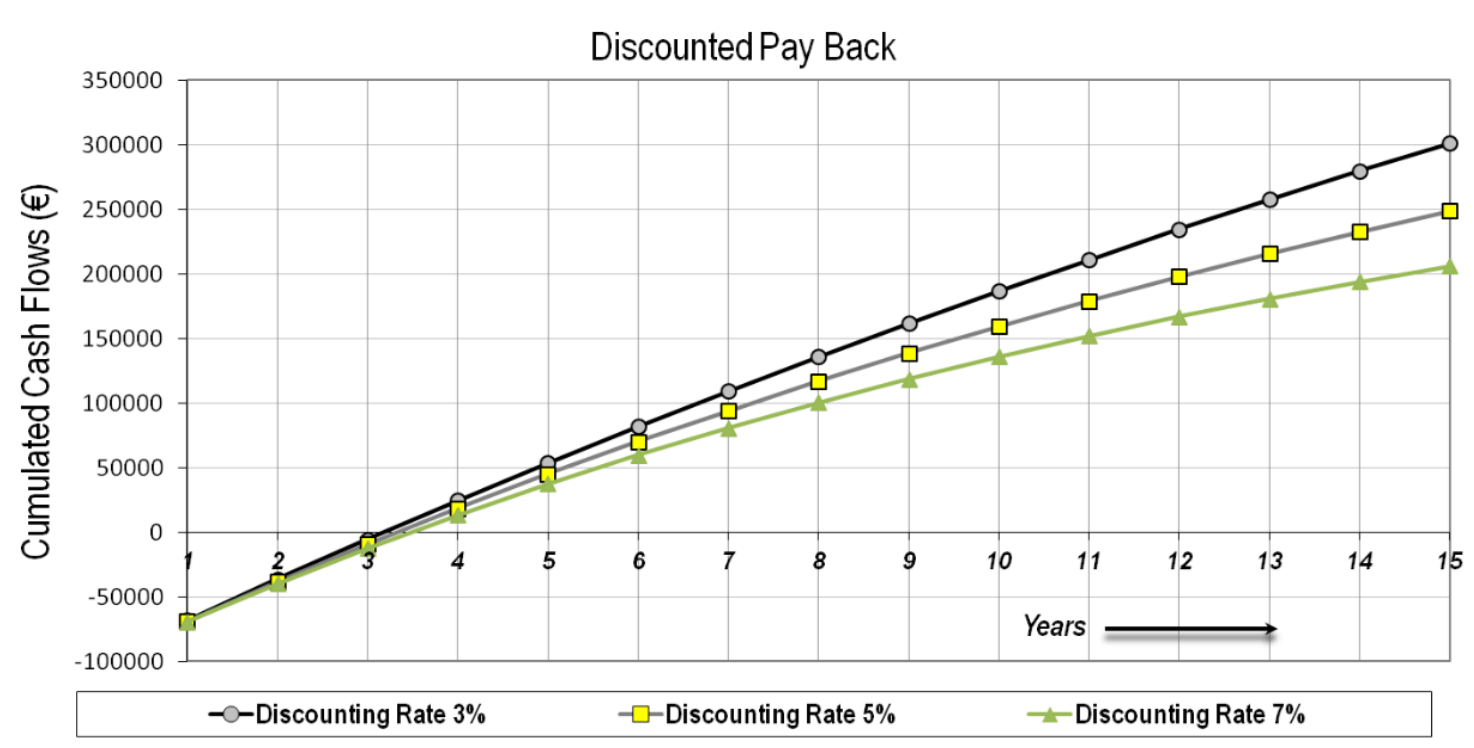

Fig. 13. Feasibility Study of the optimized system

Table 7. Performance Indexes for Temperature and Relative Humidity with change in HVAC systems

\begin{tabular}{|c|c|c|c|c|c|c|}
\hline & \multicolumn{3}{|c|}{ DOAS + Fan Coils } & \multicolumn{3}{|c|}{ DOAS + Direct Expansion } \\
\hline & Low control & Medium control & High control & Low control & Medium control & High control \\
\hline \multicolumn{7}{|c|}{ WINTER } \\
\hline $\mathrm{PI}_{\mathrm{T}}$ & $89 \%$ & $83 \%$ & $63 \%$ & $86 \%$ & $80 \%$ & $62 \%$ \\
\hline $\mathrm{PI}_{\mathrm{RH}}$ & $73 \%$ & $71 \%$ & $50 \%$ & $74 \%$ & $74 \%$ & $52 \%$ \\
\hline \multicolumn{7}{|c|}{ SUMMER } \\
\hline $\mathrm{PI}_{\mathrm{T}}$ & $97 \%$ & $87 \%$ & $94 \%$ & $97 \%$ & $87 \%$ & $94 \%$ \\
\hline $\mathrm{PI}_{\mathrm{RH}}$ & $47 \%$ & $47 \%$ & $85 \%$ & $52 \%$ & $52 \%$ & $85 \%$ \\
\hline
\end{tabular}

As previously shown, the DOAS + VRF configuration requires lower annual energy, but has a higher installation cost. This extra-cost, for the installation of the more performing system, is around $€$ 100'907. The feasibility study considers three annual discount rates for the calculation of economic indexes: (a) $3.00 \%$, (b) $5.00 \%$, (c) $7.00 \%$. Figure 13 shows the outcomes, by reporting the cumulative cash flows. The installation of a DOAS + VRF, instead of DOAS + fan coils, induces a discounted payback always lower than 8 years. Therefore, the installation cost is perfectly reasonable and also the economic investigation reveals a quite good convenience.

According to Fig. 13, by considering a lifetime equal to 15 years, the following DSB, NPV and IP (Profitability Index, i.e., the "NPV" to "Investment" ratio) have been calculated:

- Discounting Rate 3\%: DSB around 3.2 years, NPV $275 ' 195 €$, IP $=1.77$

- Discounting Rate 5\%: DSB around 3.4 years, NPV $226 ' 102 €$, IP $=1.46$

- Discounting Rate 7\%: DSB around 3.5years, NPV $186^{\prime} 036 €, \mathrm{IP}=1.21$
Obviously, the investment is as more convenient as the discounting rate is low. However, Indexes of Profit higher than $0.6 \div 0.8$ testify, generally, a good investment.

\section{Conclusion}

The study proposes a wide energy analysis of health care facilities. A real case study, the Day-Hospital building of the Italian "G. Pascale" Institute, has been investigated, starting from the building envelope refurbishment and then by analyzing several installable HVAC systems. Numerical studies have been performed after surveys and monitoring, aimed at the definitions of reliable boundary conditions (with reference to subdivision of thermal zones, microclimatic requirements, envelope structures, air-conditioning systems). The energy investigations allowed some relevant conclusions:

- The refurbishment of the building envelope is convenient, allowing more stable indoor conditions and lower energy demands

- The heating and cooling loads-due to energy transfer for transmission, radiation and infiltration through the building envelope- are significant. Therefore, 
thermal resistance and thermal inertia are strongly recommended

- Heating and cooling loads due to outdoor ventilation are very high, above all if the indoor relative humidity should be controlled. This is more evident in summer time

- The heat recovery is recommended, even if contamination of $\mathrm{OA}$ and exhaust flows must be absolutely avoided. Therefore, rotary systems and latent heat recovery devices are not suitable

- The process of sub-cooling and re-heating, in order to dehumidify the outdoor air during the cooling season is high energy-intensive. Therefore, a strict $\mathrm{RH}$ control should be designed only where necessary

- Systems that decouple sensible and latent control are preferable, by allowing diversification of thermal and IAQ controls, depending on specific necessities of the considered zone

- Direct expansion systems coupled to DOAS allow energy savings and economical convenience. This outcome derives by the higher efficiency of DX, the improved thermal transfer due to one less heat exchange and the lower energy for auxiliaries. This air-conditioning configuration is quite suitable, as confirmed by a sensitivity analysis according to three different discounting rates

Beyond optimization of building envelope (Ascione et al., 2013) and HVAC system typology (investigated in the present paper), future developments of the authors' investigation-still with reference to health care facilities-will concern energy savings achievable by optimizing all levers affecting the energy performance. More in detail, genetic algorithms and multi-objective techniques are under development for optimizing, under the technical and economical points of view, energy conservation measures, active energy systems (e.g., magnetic levitation chillers), renewable energy sources, co- and tri-generation technologies.

\section{Acknowledgement}

The authors would like to thank administration and staff of the National Institute for the Cancer Treatment "G. Pascale", in Naples, Italy. They gave us the opportunity of experiments and monitoring of the building performance. Moreover, we thank the editor and the anonymous reviewers for the advices. Surely, they contributed to an improvement of the manuscript.

\section{Author's Contributions}

Fabrizio Ascione, Nicola Bianco, Filippo de Rossi and Giuseppe Peter Vanoli: Coordinaion, data analysis and writing of the manuscript.

Rosa Francesca De Masi and Claudio De Stasio: Laterature investigations and development of numerical studies.

\section{Ethics}

The authors declare that there are not ethical issues that could arise after the publication of this study.

\section{References}

AIA, 2006. Guidelines for Design and Construction of Hospital and Healthcare Facilities. 1st Edn., American Institute of Architects Press, Washington, DC.

ANSI/ASHRAE, 2011. Standard 140-2011, standard method of test for the evaluation of building energy analysis computer programs. American Society of Heating, Refrigerating and Air-Conditioning Engineers, Atlanta, GA.

Ascione, F. and F. Minichiello, 2010. Microclimatic control in the museum environment: Air diffusion performance. Int. J. Refrigerat., 33: 806-814.

DOI: 10.1016/j.ijrefrig.2009.12.017

Ascione, F., G. de Rossi and G.P. Vanoli, 2011a. Energy retrofit of historical buildings: Theoretical and experimental investigations for the modelling of reliable performance scenarios. Energy Build., 43: 1925-36. DOI: 10.1016/j.enbuild.2011.03.040

Ascione, F., L. Bellia and F. Minichiello, 2011b. Earthto-air heat exchangers for Italian climates. Renewable Energy, 36: 2177-88. DOI: 10.1016/j.renene.2011.01.013

Ascione, F., L. Bellia, A. Capozzoli and F. Minichiello, 2009. Energy saving strategies in air-conditioning for museums. Applied Thermal Eng., 29: 676-86. DOI: $10.1016 /$ j.applthermaleng.2008.03.040

Ascione, F., N. Bianco, F. de Rossi, G. Turni and G.P. Vanoli, 2012. Different methods for the modelling of thermal bridges into energy simulation programs: Comparisons of accuracy for flat heterogeneous roofs in Italian climates. Applied Energy, 97: 405-18. DOI: 10.1016/j.apenergy.2012.01.022

Ascione, F., N. Bianco, R.F. De Masi and G.P. Vanoli, 2013a. Rehabilitation of the building envelope of Hospitals: Achievable energy savings and microclimatic control on varying the HVAC systems in Mediterranean climates. Energy Build., 60: 125-38. DOI: 10.1016/j.enbuild.2013.01.021

Ascione, F., N. Bianco, F. de Rossi and G.P. Vanoli, 2013b. Green roofs in European climates. Are effective solutions for the energy savings in airconditioning? Applied Energy, 104: 845-59. DOI: 10.1016/j.apenergy.2012.11.068 
ASHRAE, 1999. Standard 62 -1999, Ventilation for Acceptable Indoor Air Quality. 1st Edn., ASHRAE Inc., Atlanta, GA.

ASHRAE, 2011. Health care facilities, in HVAC Applications Handbook. 1st Edn., ASHRAE Inc., Atlanta, GA.

Balaras, C.A., E.I. Dascalak and A. Gaglia, 2007. HVAC and indoor thermal conditions in hospital operating rooms. Energy Build., 39: 454-70. DOI: $10.1016 /$ j.enbuild.2006.09.004

Bellia, L. and F. Minichiello, 2003. A simple evaluator of building envelope moisture condensation according to an European Standard. Build. Environ., 38: 457-68. DOI: 10.1016/S0360-1323(02)00060-4

Brent, T.G. and P.G. Ellis, 2004. Photovoltaic and solar thermal modeling with the EnergyPlus calculation engine. Proceedings of the World Renewable Energy Congress VIII, (REC' 04), Denver, Colorado.

Cao, B., Q. Shang, Z. Dai and Y, Zhu, 2013. The impact of air-conditioning usage on sick building syndrome during summer in China. Indoor Built Environ., 22: 490-497. DOI: $10.1177 / 1420326$ X12443246

CEN, 2008a. European committee for standardization, energy performance of buildings-overall energy use and definition of energy ratings. Standard EN 15603.

CEN, 2008b. European committee for standardization, energy performance of buildings-calculation of energy use for space heating and cooling. Standard EN 13790.

Crawley, D.B., J.W. Hand, M. Kummert and B.T. Griffith, 2008. Contrasting the capabilities of building energy performance simulation programs. Build. Environ., 43: 661-73. DOI: 10.1016/j.buildenv.2006.10.027

Crawley, D.B., L.K. Lawrie, C.O. Pedersen, F.C. Winkelmann and M.J. Witte et al., 2004. EnergyPlus: New, capable and linked. J. Architectural Plann. Res., 21: 292-302.

Crawley, D.B., L.K. Lawrie, F.C. Winkelmann, W.F. Buhl and Y.J. Huang et al., 2002. EnergyPlus: Creating a new-generation building energy simulation program. Energy Build., 33: 319-331. DOI: $10.1016 / \mathrm{S} 0378-7788(00) 00114-6$

DBSL, 2010. DesignBuilder Software Ltd. Version 3.1.

DIN, 2003. Standard DIN 13080-Division of hospitals into functional areas and functional sections. German Committee for Standardization.

DOE, 2012. EnergyPlus simulation software. Department of Energy, Version 7.2.0, U.S.

Harries, A., G. Brunelli and I. Rizos, 2013. London 2012 Velodrome-integrating advanced simulation into the design process, J. Build. Performance Simulat., 6: 401-419. DOI: 10.1080/19401493.2012.718796
Harriman, L., G. Brundrett and R. Kittler, 2001. Humidity control design guide for commercial and institutional buildings. ASHRAE, Inc., Atlanta, GA, USA.

Henninger, R.H. and M.J. Witte, 2011a. EnergyPlus testing with building thermal envelope and fabric load tests from ANSI/ASHRAE standard 140-2011. EnergyPlus Version 7.2.0, 2012. U.S. Department of Energy, Energy Efficiency and Renewable Energy Office of Building Technologies Washington, D.C.

Henninger, R.H. and M.J. Witte, 2011b. EnergyPlus testing with HVAC equipment performance tests CE100 to CE200 from ANSI/ASHRAE standard 140-2011. EnergyPlus Version 7.2.0, 2012. U.S. Department of Energy, Energy Efficiency and Renewable Energy Office of Building Technologies Washington, D.C.

Henninger, R.H. and M.J. Witte, 2012. EnergyPlus testing with HERS BESTEST tests from ANSI/ASHRAE standard 140-2011. EnergyPlus Version 7.2.0, 2012. U.S. Department of Energy, Energy Efficiency and Renewable Energy Office of Building Technologies Washington, D.C.

Henninger, R.H. and M.J. Witte, 2015a. EnergyPlus testing with HVAC equipment performance tests CE300 to CE545 from ANSI/ASHRAE Standard 140-2011. EnergyPlus Version 7.2.0, 2012. U.S. Department of Energy, Energy Efficiency and Renewable Energy Office of Building Technologies Washington, D.C.

Henninger, R.H. and M.J. Witte, 2015b. EnergyPlus testing with fuel-fired furnace tests HE100 to HE230 from ANSI/ASHRAE standard 140-2011. EnergyPlus Version 7.2.0, 2012. U.S. Department of Energy, Energy Efficiency and Renewable Energy Office of Building Technologies Washington, D.C.

Henninger, R.H. and M.J. Witte, 2015c. EnergyPlus testing with ASHRAE 1052-RP toolkit-building fabric analytical tests. EnergyPlus version 7.2.0, 2012. U.S. Department of Energy, Energy Efficiency and Renewable Energy Office of Building Technologies Washington, D.C.

Henninger, R.H. and M.J. Witte, 2015d. EnergyPlus testing with IEA BESTEST in-depth ground coupled heat transfer tests related to slab-on-grade construction. EnergyPlus Version 7.2.0, 2012. U.S. Department of Energy, Energy Efficiency and Renewable Energy Office of Building Technologies Washington, D.C.

Henninger, R.H. and M.J. Witte, 2015e. EnergyPlus testing with IEA BESTEST multi-zone non-airflow in-depth diagnostic cases MZ320-MZ360. EnergyPlus Version 7.2.0, 2012. U.S. Department of Energy, Energy Efficiency and Renewable Energy Office of Building Technologies Washington, D.C. 
Henninger, R.H. and M.J. Witte, 2015f. EnergyPlus testing with HVAC equipment component tests. EnergyPlus Version 7.2.0, 2012. U.S. Department of Energy, Energy Efficiency and Renewable Energy Office of Building Technologies Washington, D.C.

Henninger, R.H. and M.J. Witte, 2015g. EnergyPlus testing with IEA BESTEST mechanical equipment and control strategies for a chilled water and a hot water system. EnergyPlus Version 7.2.0, 2012. U.S. Department of Energy, Energy Efficiency and Renewable Energy Office of Building Technologies Washington.

Henninger, R.H. and M.J. Witte, 2015h. EnergyPlus testing with global energy balance test. EnergyPlus Version 7.2.0, 2012. U.S. Department of Energy, Energy Efficiency and Renewable Energy Office of Building Technologies Washington, D.C.

IMPW, 1974. Italian Ministry for Public Works. Circular n. 13011.

ISO, 1994. International organization for standardization, thermal insulation. Building Elements: In-Situ Measurement of Thermal Resistance and Thermal Transmittance. Standard ISO 9869.

ISO, 2007. International organization for standardization building components and building elements: Thermal resistance and thermal transmittance, calculation method. Standard ISO EN 6946.

ISPESL, 2002. Guidelines for the definition of safety standards and environmental health for departments of operators. Italian National Institute for Prevention and Work Safety.

Lomas, K.J. and R. Giridharan, 2012. Thermal comfort standards, measured internal temperatures and thermal resilience to climate change of free-running buildings: A case-study of hospital wards. Build. Environ., 55: 57-72.

DOI: 10.1016/j.buildenv.2011.12.006

Lomas, K.J., R. Giridharan, C.A. Short and A.J. Fair, 2012. Resilience of 'Nightingale' hospital wards in a changing climate. Build. Services Eng. Res. Technol., 1: 81-103. DOI: $10.1177 / 0143624411432012$

Ma, L., P. Cooper, D. Daly and L. Ledo, 2012. Existing building retrofits: Methodology and state-of-the-art. Energy Build., 55: 889-902. DOI: 10.1016/j.enbuild.2012.08.018

Neymark, J. and R. Judkoff, 2001. International energy agency solar heating and cooling programme Task 22 Building Energy Simulation Test and diagnostic method for HVAC equipment models (HVAC BESTEST). National Renewable Energy Laboratory, Golden, Colorado.
Neymark, J. and R. Judkoff, 2008a. International Energy Agency Building Energy Simulation TEST and Diagnostic Method (IEA BESTEST) in-depth diagnostic cases for ground coupled heat transfer related to slab-on-grade construction. NREL/TP550-43388, National Renewable Energy Laboratory, Golden, Colorado.

Neymark, J. and R. Judkoff, 2008b. International Energy Agency Building Energy Simulation TEST and Diagnostic Method (IEA BESTEST) multi-zone non-airflow in-depth diagnostic cases: MZ320MZ360, NREL/TP-550-43827. National Renewable Energy Laboratory, Golden, Colorado.

Olsen, E.L. and Q. Chen, 2003. Energy consumption and comfort analysis for different low-energy cooling systems in a mild climate. Energy Build., 35: 560-71. DOI: 10.1016/S0378-7788(02)00164-0

Ozyogurtcu, G., M. Mobedi and B. Ozerdem, 2011. Economical assessment of different HVAC systems for an operating room: Case study for different Turkish climate regions. Energy Build., 43: 1536-43. DOI: 10.1016/j.enbuild.2011.02.013

PIR, 1997. President of Italian Republic. Presidential Decree 14th January 1997.

Rempela, A.R., A.W. Rempelb, K.W. Cashmanb, K.N. Gatesc and C.J. Paged et al., 2013. Interpretation of passive solar field data with EnergyPlus models: Un-conventional wisdom from four sunspaces in Eugene, Oregon. Build. Environ., 60: 158-72.

DOI: $10.1016 /$ j.buildenv.2012.11.006

San José-Alonso, J.F., E. Velasco-Gomez, F.J. ReyMartínez, M. Alvarez-Guerra and C. Gallego Peláez, 1999. Study on environmental quality of a surgical block. Energy Build., 29: 179-87. DOI: $10.1016 / \mathrm{S} 0378-7788(98) 00058-9$

Short, C.A., K.J. Lomas, R. Giridharan and A.J. Fair, 2012. Building resilience to overheating into 1960's UK hospital buildings within the constraint of the national carbon reduction target: Adaptive strategies. Build. Environ., 55: 73-95. DOI: 10.1016/j.buildenv.2012.02.031

Shrestha, S. and G. Maxwell, 2011. Empirical validation of building energy simulation software: Energyplus. Proceedings of the 12th Conference of International Building Performance Simulation Association, Nov. 14-16, Sydney.

Spitler, J.D., S.J. Rees and X. Dongyi, 2001. ASHRAE 1052-RP FINAL REPORT titled Development of an Analytical Verification Test Suite for Whole Building Energy Simulation Programs-Building Fabric, ASHRAE2001. 
Stefanutti, L., 1996. Applicazioni di impianti di climatizzazione. Hospital, Tecniche Nuove Editor.

Strand, R.K. and K.T. Baumgartner, 2005. Modeling radiant heating and cooling systems: Integration with a whole-building simulation program. Energy Build., 37: 389-97.

DOI: $10.1016 /$ j.enbuild.2004.07.009

Sun, Z., S. Wang and N. Zhu, 2011. Model-based optimal control of outdoor air flow rate of an airconditioning system with primary air-handling unit. Indoor Built Environ., 20: 626-637. DOI: $10.1177 / 1420326 X 11411511$

UNI, 1995. Italian organization for standardization, HVAC for indoor comfort. General, classification and requirements. Rules for the inquiry, offer, order and delivery, Standard UNI 10339.

Van Hoof, J., H.S.M. Kort, M.S.H. Duijnstee, P.G.S. Rutten and J.L.M. Hensen, 2010a. The indoor environment and the integrated design of homes for older people with dementia. Build. Environ., 45: 1244-61. DOI: 10.1016/j.buildenv.2009.11.008

Van Hoof, J., H.S.M. Kort, J.L.M. Hensen, M.S.H. Duijnstee and P.G.S. Rutten, 2010b. Thermal comfort and the integrated design of homes for older people with dementia. Build. Environ., 45: 358-70. DOI: 10.1016/j.buildenv.2009.06.013

Yu, C.W.F. and J.T. Kim, 2012. Low-carbon housings and indoor air quality. Indoor Built Environ., 21: 5-15. DOI: $10.1177 / 1420326 X 11431907$

Zhou, Y.P., J.W. Wu, R.Z. Wang, S. Shiochi and Y.M. $\mathrm{Li}, 2008$. Simulation and experimental validation of the Variable-Refrigerant-Volume (VRV) airconditioning system in EnergyPlus. Energy Build., 40: 1041-7. DOI: 10.1016/j.enbuild.2007.04.025

\section{Nomenclature}

$\begin{array}{lll}\text { Symbols, } & \text { Units and Subscripts } & \\ \lambda & \text { Thermal conductivity } & {[\mathrm{W} / \mathrm{mK}]} \\ \mathrm{U}_{\mathrm{VALUE}} & \text { Thermal transmittance } & {\left[\mathrm{W} / \mathrm{m}^{2} \mathrm{~K}\right]} \\ \mathrm{ACH} & \text { Air Changes per Hour } & {\left[\mathrm{h}^{-1}\right]} \\ \mathrm{T} & \text { Temperature } & {[--]} \\ \mathrm{RH} & \text { Relative Humidity } & {[--]} \\ \eta & \text { Efficiency(general symbol) } & {[--]} \\ \mathrm{COP} & \text { Coefficient of Performance } & {\left[\mathrm{W}_{\mathrm{TH}} / \mathrm{W}_{\mathrm{EL}}\right]} \\ \eta_{\mathrm{REC}} & \text { Heat Recovery Efficiency } & {[--]} \\ \mathrm{PI}_{\mathrm{T}} & \text { Performance Index for } & {[\%]} \\ & \text { Air Temperature } & {[\%]} \\ \mathrm{PI}_{\mathrm{RH}} & \text { Performance Index for } & \\ & \text { Relative Humidity } & {[\mathrm{years}]} \\ \mathrm{DPB} & \text { Discounted Pay Back } & {[€]} \\ \mathrm{NPV} & \text { Net Present Value Index } & {[-]} \\ \mathrm{IP} & \text { Index of Profit (i.e., NPV/COST) }\end{array}$

Simple Acronyms

HVAC Heating, Ventilating and Air-Conditioning System

VRF Variable Refrigerant Volume

VAV Variable Air Volume

DOAS Dedicated Outdoor Air Systems

FC Fan Coil Units

DX Direct Expansion Coil

AHU Air Handling Unit

OA Outdoor Air

IAQ Indoor Air Quality

DHW Domestic Hot water

BEPS Building Energy Performance Simulation 